\title{
Protein Kinase C Modulation of Recombinant NMDA Receptor Currents: Roles for the C-Terminal C1 Exon and Calcium lons
}

\author{
Stephen M. Logan, ${ }^{1}$ Felix E. Rivera, ${ }^{2}$ and John P. Leonard ${ }^{1}$ \\ ${ }^{1}$ Department of Biological Sciences, University of Illinois at Chicago, Chicago, Illinois 60607-7056, and 2Department of \\ Biology, Cayey University College, Cayey, Puerto Rico 00736
}

\begin{abstract}
Protein kinase $C(P K C)$ positively modulates NMDA receptor (NMDAR) currents. In contrast to previous reports, this study determines the importance of individual exons in the mechanism underlying the potentiation process by examining the complete set of eight naturally occurring splice variants expressed in Xenopus oocytes both as homomers and as heteromeric NR1/NR2A or NR1/NR2B complexes. After PKC stimulation, homomeric currents demonstrated a high level of potentiation ( $\sim 500 \%$ of untreated baseline currents) that reduced to a lower level ( $\sim 300 \%$ of baseline) in variants containing the first C-terminal exon (C1). An ANOVA showed that only $\mathrm{C} 1$ and no other exon or interaction of exons determined the degree of NMDAR current modulation by PKC. When recordings were performed in solutions in which barium replaces calcium, only the lower form of potentiation was observed, regardless of the splice variant exon composition. This sug-
\end{abstract}

gested an important role for calcium in the PKC modulation of homomeric NMDA splice variant currents in which the $\mathrm{C} 1$ exon also participates. The effectiveness of the $\mathrm{C} 1$ exon to reduce the higher form of potentiation is modulated by heteromeric assemblies with NR2A heteromers yielding smaller levels of potentiation and a larger $\mathrm{C} 1$ exon effect compared with NR2B heteromers. The heteromers demonstrated the higher form of potentiation even in the absence of calcium. Furthermore, calcium had different effects in the potentiation of the heteromers depending on the NR2 subunit. This study refines the region of the NR1 subunit involved in a modulation crucial to the function of NMDA receptors and provides evidence that the NR2A and NR2B subunits realize this modulation differentially.

Key words: NR1; NR2; NMDAR; alternative splicing; variants; Xenopus oocytes; barium; phorbol ester; homomer; heteromer
The NMDA subtype of glutamate receptor (NMDAR) sits at the crux of several processes critical to nervous system function, including activity-dependent forms of synaptic plasticity such as dendritic refinement in synaptogenesis (Collingridge and Singer, 1990; Constantine-Paton et al., 1990) and long-term potentiation (Bliss and Collingridge, 1993; Nicholl and Malenka, 1995; Tsien et al., 1996). Protein kinase C (PKC) positively modulates NMDAR currents in rat dorsal horn neurons (Gerber et al., 1989), dentate (Obokata et al., 1997) and CA1 neurons (Lozovaya and Klee, 1995) of rat hippocampal slices, and cultured trigeminal neurons (Chen and Huang, 1991, 1992). Currents expressed from oocytes injected with either total rat brain mRNA (Kelso et al., 1992; Urushihara et al., 1992) or with mRNA prepared from clones in vitro (Durand et al., 1993; Yamakura et al., 1993; Wagner and Leonard, 1996; Zheng et al., 1997) are similarly potentiated by phorbol application.

The gene encoding the necessary NR1 subunit contains three exons that are alternatively spliced to form eight distinct subunit variants (Durand et al., 1993; Hollmann et al., 1993; Zukin and Bennett, 1995). When injected into Xenopus oocytes, these subunits are able to form functional homomeric channels, each

\footnotetext{
Received Oct. 6, 1998; accepted Nov. 20, 1998.

This work was supported by National Institutes of Health Grant NS31962. We thank Georgia Vlachogiannis for her excellent technical assistance with the work presented here. We also thank Dr. Joel Brown of the Biological Sciences Department for his critical evaluation of the statistical methods used in the analysis of our data, and Drs. R. Paul Malchow, A. Don Murphy, Christopher Comer, and Gianluca Gallo for their assistance in the preparation of this manuscript. We also thank Dr. Jim Boulter for his generosity in supplying us with all the clones used in the experiments.

Copyright (C) 1999 Society for Neuroscience $\quad 0270-6474 / 99 / 190974-13 \$ 05.00 / 0$
}

exhibiting unique pharmacological (Sugihara et al., 1992; Durand et al., 1993; Hollmann et al., 1993; Zheng et al., 1994; Traynelis et al., 1995) and functional profiles, including modulation by PKC (Durand et al., 1993; Zheng et al., 1997). Native NMDARs are likely to exist in a heteromeric arrangement of NR1 subunits with two or more of the closely related NR2 subunits (NR2A-2D) (Monyer et al., 1992; Ishii et al., 1994). Of the possible heteromeric arrangements, only NR2A and NR2B subunits are known to permit the PKC modulation of currents.

The molecular events underlying the PKC-induced potentiation of NMDAR currents remain elusive. Studies using biochemistry and immunohistochemistry have shown that PKC phosphorylates the NR1 and NR2 subunits directly (Tingley et al., 1993, 1997; Ehlers et al., 1995; Hall and Soderling, 1997). Serine residues located in the alternatively spliced C1 exon of the NR1 subunit are the most heavily phosphorylated component of the receptor (Tingley et al., 1993, 1997). Paradoxically, the presence of the C-terminal tail leads to smaller current potentiation (Durand et al., 1992, 1993; Zheng et al., 1997). Domains of the NR2 subunits are also implicated in PKC modulation of NMDAR currents (Kutsuwada et al., 1992; Mori et al., 1993). However, functional studies have failed to demonstrate the existence of any key residue in either NR1 or NR2 subunits which, when phosphorylated, results in current enhancement (Yamakura et al., 1993; Sigel et al., 1994). Potentiation of currents by PKC therefore could result either from direct phosphorylation of the receptor itself or by the activation of some process involving an associated regulatory protein.

In the present study, all eight splice variants were expressed as homomers and as NR1/NR2A and NR1/NR2B heteromers re- 
sulting in observations that differ quantitatively and qualitatively from previous results collected from a limited subset of variants (Durand et al., 1992, 1993; Zheng et al., 1997). Importantly, this study provides strong evidence that the first $\mathrm{C}$-terminal exon $(\mathrm{C} 1)$ of the NR1 subunit is solely responsible for the modulation of PKC potentiation, with the absence of the $\mathrm{C} 1$ exon leading to a higher level of potentiation. This high degree of potentiation is dependent on calcium, suggesting a role for calcium-sensitive proteins in the potentiation of the homomers, but does not involve a "rapid calcium amplification" as proposed by Zheng et al. (1997). In contrast to conclusions from previous studies (Durand et al., 1992, 1993; Zheng et al., 1997), neither the N-terminal exon (N1) nor the second C-terminal exon (C2) participates in the potentiation of homomeric or heteromeric currents, and the degree of potentiation does not correlate with baseline current size. Furthermore, this study clearly demonstrates an unwritten assumption underlying all previous studies that exons do not interact to produce potentiation. The effectiveness of the $\mathrm{C} 1$ exon to reduce the higher form of potentiation is modulated by heteromeric assemblies with NR2A heteromers yielding smaller levels of potentiation and a larger $\mathrm{C} 1$ exon effect compared with NR2B heteromers. Such differential modulation may be critical to activity-dependent processing in the CNS.

\section{MATERIALS AND METHODS}

Splice variant nomenclature. Members of the NR1 subunit family are generated by a gene that contains 22 exons, three of which are alternative-spliced to generate eight possible variants: an N-terminal exon, Exon 5 (N1), which encodes for 21 amino acids, and two C-terminal exons, Exon 21 (C1) and Exon 22 (C2), which encode for 37 and 38 amino acids, respectively. The splicing event that removes $\mathrm{C} 2$ results in a new open reading frame that encodes a novel 22 amino acid sequence before reaching the new stop codon (Sugihara et al., 1992; Durand et al., 1993; Hollmann et al., 1993; Zheng et al., 1997). The nomenclature is that used by Durand et al. (1993) in which a " 0 " or a " 1 " indicates the absence or presence, respectively, of an exon in the $5^{\prime}-3^{\prime}$ order N1, C1, C2. For example, the splice variant NR1-011 corresponds to the following exon arrangement: $\mathrm{N} 1$ absent, $\mathrm{C} 1$ present, $\mathrm{C} 2$ present. Note that an "X" is used to denote that the exon in the position marked by an X may either be present or absent. Thus, C1-containing variants will be marked as NR1-X1X.

cRNA synthesis. The cDNA clones encoding the NR1 splice variants (pNMDAR1-1a-pNMDAR1-4b) (Hollmann et al., 1993) and those encoding members of the NR2 gene family [pNR2A251 (NR2A) and pJS2B (NR2B)] (Monyer et al., 1992) were gifts from Dr. J. Boulter (Salk Institute, San Diego, CA). To generate full-length coding transcripts of the NR1 variants, the plasmid was linearized using either EcoRV or NheI, which cuts at the junction between the $3^{\prime}$ untranslated region of the insert and the pBluescript SK (-) vector. The plasmid containing the cDNA for NR2A was linearized using EcoRI, whereas the NR2Bcontaining plasmid was linearized using NotI. The transcription reaction was performed using the mRNA capping kit from Stratagene (La Jolla, CA) in which a 10 -fold molar excess of $\left(5^{\prime}\right) \mathrm{GpppG}\left(5^{\prime}\right)$ to GTP was included (Drummond et al., 1985). The cap was used to protect the synthetic RNA from being rapidly degraded during injection into oocytes (Kreig and Melton, 1984).

T3 RNA polymerase was used to transcribe sense RNA (except NR2B, T7) from $4 \mu \mathrm{g}$ of linearized plasmid treated with proteinase K. As a modification to the standard procedure suggested by Stratagene, all reactants were doubled, and $10 \mathrm{U}$ of RNA polymerase was added to the reaction after the first half hour of incubation and the reaction was continued for another half hour. The purified cRNA pellet was resuspended in autoclaved double-distilled water $\left(\mathrm{ddH}_{2} \mathrm{O}\right)$ at a concentration of $0.1-0.25 \mu \mathrm{g} / \mathrm{ml}$. The cRNA was first checked on a $1.1 \%$ agarose gel containing $2.2 \mathrm{M}$ formaldehyde and $1 \times$ MOPS buffer (Maniatis et al., 1982) to assure integrity of the transcript and to estimate the amount of cRNA present.

Preparation of Xenopus oocytes. Oocytes were surgically removed from adult female Xenopus laevis frogs that were anesthetized before surgery with a $0.2 \%$ MS-222 (3-amino-benzoic acid ethylester) solution contain- ing $0.2 \%$ sodium bicarbonate as a buffer. Follicular cells and connective tissue were removed by agitation in $2 \mathrm{mg} / \mathrm{ml}$ collagenase (type IA; Sigma, St. Louis, MO) for $2 \mathrm{hr}$ in $\mathrm{Ca}^{2+}$-free solution $(82.5 \mathrm{~mm} \mathrm{NaCl}, 2 \mathrm{~mm} \mathrm{KCl}$, $1 \mathrm{mM} \mathrm{MgCl}_{2}, 5 \mathrm{~mm}$ HEPES, pH 7.5). When $50 \%$ of the oocytes were denuded, the cells were washed extensively, and stages IV and V oocytes were selected. Healthy oocytes were injected with 50-70 $\mathrm{nl}$ aqueous samples of $0.25-1.0 \mathrm{ng} / \mathrm{nl}$ in vitro-transcribed mRNA to form homomers, or cRNAs of appropriate NR1 and NR2 subunits were mixed in a 10:1 molar ratio to form heteromers. Injection was achieved using an automatic $10 \mu \mathrm{l}$ microdispenser (Drummond "Nanoject"; Broomall, PA) mounted on a micromanipulator. To allow the expression of the exogenous cRNA, injected oocytes were incubated $1-7 \mathrm{~d}$ at $20^{\circ} \mathrm{C}$ for homomers or 1-3 d for heteromers in the following medium: $96 \mathrm{~mm} \mathrm{NaCl}, 2 \mathrm{~mm}$ $\mathrm{KCl}, 1.8 \mathrm{~mm} \mathrm{CaCl}_{2}, 1 \mathrm{~mm} \mathrm{MgCl}_{2}, 5 \mathrm{~mm}$ HEPES, $2.5 \mathrm{~mm}$ pyruvate, and $100 \mu \mathrm{g} / \mathrm{ml}$ gentamicin. The dishes were kept in a humid atmosphere, and the solution was replaced at least once each day. Under these conditions the oocytes can be maintained in good health for up to $10 \mathrm{~d}$. Expressed channels were observable 2-3 d after injection and may be studied for an additional $7 \mathrm{~d}$.

Recording solutions. Experiments were performed in nominally $\mathrm{Mg}^{2+}$. free solutions in which the divalent cation composition was replaced entirely by either $\mathrm{CaCl}_{2}(\mathrm{COS})$ or $\mathrm{BaCl}_{2}$ (BOS). These solutions contain $96 \mathrm{~mm} \mathrm{NaCl}, 2 \mathrm{~mm} \mathrm{KCl}, 5 \mathrm{~mm}$ HEPES, $\mathrm{pH} 7.5$, and $2.8 \mathrm{~mm}$ of the replacing divalent cation. Omission of $\mathrm{Mg}^{2+}$ ions has no effect on the PKC sensitivity of recombinant NMDARs (Wagner and Leonard, 1996). Frozen $1 \mathrm{~mm}$ stock solutions of 12,13-phorbol ester dibutyrate (PDBu; Sigma) in dimethylsulfoxide (DMSO) were diluted in recording solution to yield a working concentration of $20 \mathrm{nM}$ PDBu, 0.01\% DMSO. A 400 mM stock solution of niflumic acid (NFA; Sigma) was prepared in DMSO and diluted to yield a working concentration of $200 \mu \mathrm{M}$ NFA, $0.005 \%$ DMSO in the following way: $500 \mu \mathrm{l}$ of the NFA stock (400 mM) was diluted into $50 \mathrm{ml}$ of $50 \mathrm{~mm} \mathrm{NaOH}$ with rigorous shaking. This was added to $880 \mathrm{ml}$ of stirring ddH $\mathrm{H}_{2} \mathrm{O}$ after which $250 \mu \mathrm{l}$ of $12 \mathrm{~N} \mathrm{HCl}, 50 \mathrm{ml}$ of a $20 \times$ stock solution of unbuffered saline $(2 \mathrm{M} \mathrm{NaCl}$ and $400 \mathrm{~mm} \mathrm{KCl}), 10$ $\mathrm{ml}$ of a $100 \times \mathrm{CaCl}_{2}$ stock $\left(280 \mathrm{mM} \mathrm{CaCl}_{2}\right)$, and $10 \mathrm{ml}$ of a $100 \times$ HEPES buffer stock (100 mM HEPES, $\mathrm{pH}$ 7.5) were all added in the sequence given. The solution was adjusted to $\mathrm{pH} 7.5$ and stored in a light-tight container at $4^{\circ} \mathrm{C}$.

Electrophysiological techniques. Currents were recorded with a Warner oocyte clamp (OC-725a) (Warner Instrument Corp., Hamden, CT) using two-electrode voltage-clamp techniques, and the data were collected and analyzed using PCLAMP software (Axon Instruments, Foster City, CA). The glass recording electrodes were pulled using a Flaming Brown micropipette puller (Sutter Instruments, Navato, CA) to resistances of 1-3 $\mathrm{M} \Omega$ and were filled with $3 \mathrm{~mm} \mathrm{KCl}$. Oocytes were recorded in a continuous flow chamber apparatus with a volume of $400 \mu \mathrm{l}$. NMDA responses evoked using a $20 \mathrm{sec}$ bath perfusion of agonist solution (recording solution containing $100 \mu \mathrm{M}$ NMDA and $100 \mu \mathrm{M}$ glycine) were recorded while the membrane was voltage clamped at $-80 \mathrm{mV}$.

To examine the effect that PKC stimulation has on currents, oocytes were incubated for $8 \mathrm{~min}$ in the presence of PDBu $(20 \mathrm{nM})$, which was followed by a 1 min wash before agonist application. The wash time is sufficient to clear the chamber of PDBu, although the chemical may still remain in the oocyte for some time afterward. Currents are elicited at 2 min time intervals after the wash to generate a time course for the peak current size after phorbol. For both baseline and potentiated currents, measurements were made $20 \mathrm{sec}$ after the onset of the response was initiated. The degree of potentiation was expressed as a ratio of the current measured after stimulation by phorbol to the baseline current obtained before phorbol application. Because the degree of potentiation was dependent on the measured baseline current size, obtaining a stable baseline was of paramount importance. Only when the baseline did not differ more than $\pm 10 \%$ for two consecutive 8 min intervals (equivalent to the time of phorbol incubation) was it considered stable.

The oocyte expression system demonstrates variation in terms of baseline current size as well as in the degree of modulation expressed by PKC activation. To compensate for this inherent variability, cRNA for each of the eight splice variants was injected into 20-30 oocytes from the same batch or oocytes that were taken from the same frog. These methods compensate for individual variation expressed by a particular frog or batch of oocytes because these nonspecific effects will be realized across all eight of the splice variants.

Statistical considerations. Because the magnitude of the PKC potentiation shows both batch and frog dependence, all eight splice variants (either in homomeric or heteromeric configurations) were injected into 
Xenopus oocytes from the same frog. Recordings were made from all splice variants on a given day in a random order. Additionally, for the heteromeric data, to allow for the best comparison between recordings in calcium and barium, a particular splice variant was recorded in both conditions within a $2 \mathrm{hr}$ time period. The data represent recordings from a minimum of three different frogs. In this way, the experiments were blocked for effects of time and frog, thus reducing their biasing the data set for any particular splice variant.

All of the data presented in the figures represent the means with the Standard Error of the Mean ( \pm SEM). Statistical analysis was performed using the paired and unpaired Student's $t$ test (Sigma Plot for Windows, V3; Jandel Scientific, San Rafael, CA) and a three-way ANOVA (Systat 6.0; SPSS Inc., Chicago, IL) in which the three exons were considered independent variables with two levels each (presence or absence) and the degree of potentiation was considered the dependent variable. The contribution that individual exons make to the variation in the degree of potentiation could be examined using this analysis. Additionally, the degree to which possible interactions between exons contribute to the variation could be examined. A four-way ANOVA (Systat 6.0) was also conducted in which the frog was considered an independent variable with three or four levels (depending on the number of frogs used in the study) in addition to the independent variables considered in the three-way ANOVA. This four-way ANOVA allowed a statistical removal of nonspecific effects attributable to individual batches of oocytes. In the case of all statistical tests used, a result was considered significant given a $p$ value of $<0.05$.

\section{RESULTS}

\section{Phorbol ester potentiates currents from homomeric NR1 splice variants to differing degrees in the presence of calcium}

Previous work in this as well as in several other laboratories established that currents evoked from NMDA receptors expressed either from total rat brain mRNA (Kelso et al., 1992; Urushihara et al., 1992) or from cRNA (Kutsuwada et al., 1992; Yamazaki et al., 1992; Wagner and Leonard, 1996) are positively modulated by activators of PKC in Xenopus oocytes. This basic phenomenon is demonstrated in Figure $1 A$, which shows the potentiation of homomeric currents expressed from the NR1-000 splice variant cRNA (nomenclature discussed in Materials and Methods) before (Pre-PDBu) and after (Post-PDBu) an $8 \mathrm{~min}$ exposure to the PKC activating agent PDBu $(20 \mathrm{nM})$. The cells were clamped at $-80 \mathrm{mV}$ in a $\mathrm{Mg}^{2+}$-free solution in which calcium replaces magnesium (COS, $2.8 \mathrm{mM} \mathrm{Ca}^{2+}$, final), and currents were elicited using a $20 \mathrm{sec}$ application of agonist (100 $\mu \mathrm{M}$ NMDA, $100 \mu \mathrm{M}$ glycine; saturating for both) followed by a COS wash. Omission of $\mathrm{Mg}^{2+}$ ions from the recording solutions does not affect the PKC sensitivity of recombinant NMDARs (Wagner and Leonard, 1996).

To avoid a large portion of current contamination by the initial, highly variable, inward peak (Fig. $1 A$ ), all currents are measured $\sim 20 \mathrm{sec}$ after the initialization of the inward current. The potentiation is expressed as a percentage increase from a stabilized baseline current established before incubation in the presence of PDBu (discussed in Materials and Methods). These values are averaged, and the mean potentiation \pm SEM is recorded in bar charts shown in Figure $1 B$ and throughout.

Frog oocytes were injected with the cRNA for each of the splice variants to form homomeric NMDARs, as described in Materials and Methods. Figure $1 B$ shows that after PKC stimulation with phorbol, currents from the splice variants ranged from $\sim 300$ to $500 \%$ (an approximately three- to fivefold increase) over their initial baseline values when the experiments were performed in the presence of calcium. Additionally, the splice variants divide themselves into two groups based on their ability to be potentiated by $\mathrm{PKC}$ activation: high responders that range from
460 to $510 \%$ of baseline currents (NR1-001, $460 \pm 35 \%$; NR1$101,460 \pm 31 \%$; NR1-000, $510 \pm 39 \%$; NR1-100, $500 \pm 34 \%$ ) and low responders that range between 310 and $380 \%$ of baseline currents (NR1-011, $320 \pm 20 \%$; NR1-111, $310 \pm 21 \%$; NR1$110,310 \pm 22 \%$; NR1-010, $380 \pm 31 \%$ ). In all cases, pairwise comparisons made between splice variants, which only differ in their exon composition by the presence or absence of $\mathrm{C} 1$ (plotted adjacent to each other in Fig. $1 B$ ), were significantly different from each other with $\mathrm{C} 1$ presence always giving rise to a lower degree of potentiation ( $p<0.01$ for all by Student's $t$ test) (Fig. $1 B$, asterisks).

\section{In barium replacement solution, homomeric currents are not differentially potentiated by PKC}

Oocytes are known to possess endogenous chloride channels that are activated by increases in internal calcium concentration and give rise to a well characterized inward chloride conductance (Barish, 1983; Miledi and Parker, 1984; Boton et al., 1989). Thus, the initial peak of inward current, shown in Figure $1 A$, is not caused by receptor desensitization or inactivation but rather is caused by the activation of $\mathrm{Ca}^{2+}$-dependent chloride channels by calcium permeation through the NMDARs (Leonard and Kelso, 1990). The effect may be enhanced in the experiments presented here because the recording solution (COS) contains a $2.8 \mathrm{~mm}$ final concentration of calcium ions compared with a $1.8 \mathrm{~mm}$ concentration found at physiological levels. Barium, which is a poor activator of this channel, is often used as a substitute in physiological solutions to severely reduce the contribution of this contaminating current (Barish, 1983; Miledi and Parker, 1984; Leonard and Kelso, 1990). Thus, the initial transient peak seen when recording from NR1-000 currents in COS (Fig. 1A) is eliminated when recording from the same splice variant in a solution in which barium replaces calcium ions and magnesium ions (BOS) (Fig. 2A). Note that the scale is seven times larger for the traces in Figure $1 A$ compared with Figure $2 A$. This reflects the fact that, in general, the currents recorded in BOS are smaller than those recorded in COS (means of $11.7 \pm 1.0 \mathrm{nA}$ vs $17.3 \pm 0.8$ $\mathrm{nA}$ ), with certain splice variants being more affected by barium in this regard than others. For example, NR1-001 and NR1-000 showed more than a twofold reduction in current size when recording in barium, whereas NR1-111 and NR1-110 showed only very minimal effects.

To investigate whether the type of divalent cation present in the recording solution affects the degree of homomeric current potentiation by PKC activators, oocytes from the same batch were injected with cRNA for each of the splice variants and were recorded in barium-containing solutions (BOS). These experiments were run identically to the procedures outlined above in which all solutions contained calcium (COS). The results in Figure $2 B$ show that in barium solutions (black bars) the variants do not differ significantly from each other in terms of their modulation, with an average potentiation of $315 \pm 10 \%(n=80)$ over the established baseline currents, (analysis by three-way and four-way ANOVA). For a particular splice variant, the data obtained in COS (Fig. 2B, open bars) was compared with that obtained in BOS using the Student's $t$ test. Variants demonstrating a significant difference between the two conditions were those that lack $\mathrm{C} 1$ (Fig. 2B, asterisks). In each of these NR1-X0X variants, the potentiation seen when recording in calciumcontaining solutions was much greater than that seen when recording in barium solutions (NR1-001, $40.5 \%$ greater potentiation in COS vs BOS, $p=0.034$; NR1-101, $40.7 \%$ greater, $p=$ 
A cos

\section{NMDA/Gly}
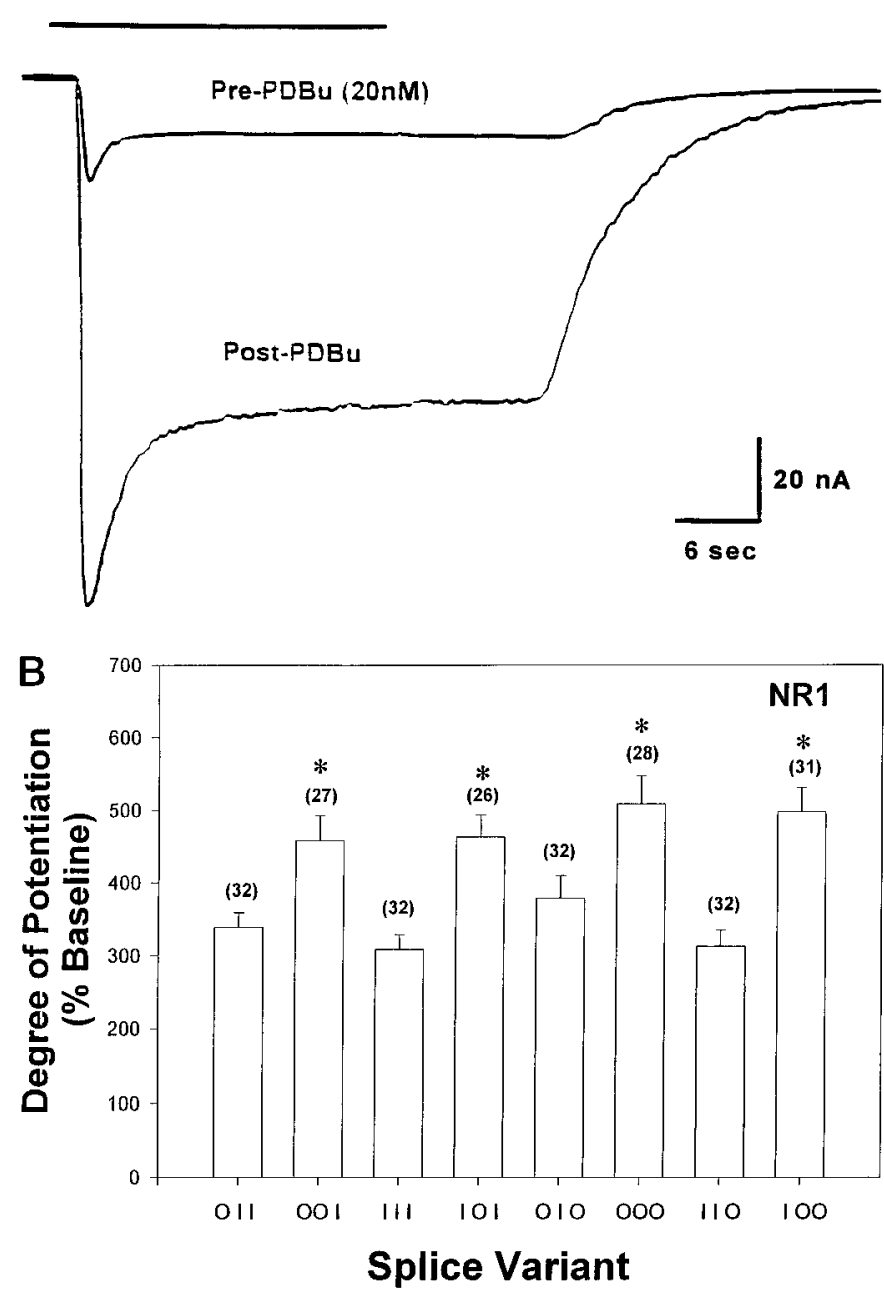

Figure 1. A, Phorbol-induced potentiation of homomeric NR1 receptor currents expressed in Xenopus oocytes. Cells expressing NR1-000 variants were clamped at $-80 \mathrm{mV}$ in calcium replacement solutions $(C O S)$, and currents were elicited using an $\sim 20 \mathrm{sec}$ application of agonist $(100 \mu \mathrm{M}$ NMDA, $100 \mu \mathrm{M}$ glycine) followed by agonist wash-out. After a stable baseline $(P r e-P D B u)$ was attained, the oocytes were incubated for $8 \mathrm{~min}$ in the PKC-activating agent phorbol ester dibutyrate (PDBu; $20 \mathrm{~nm})$. The current trace demonstrating the peak level of potentiation induced by $\mathrm{PDBu}$ treatment is shown (Post-PDBu). $B$, When recording in the presence of calcium (COS), NR1 splice variants that do not contain the C1 exon (NR1-X0X) yield a significantly higher degree of current potentiation by PDBu compared with those variants that do contain C1 (NR1$\mathrm{X} 1 \mathrm{X})$. Xenopus oocytes from a particular frog were injected with in vitro-transcribed RNA for each of the eight splice variants and were allowed to express 2-7 d in culture before recording. Currents were elicited as described in $A$. All currents were measured $20 \mathrm{sec}$ after the initiation of the inward current. The bars represent the degree of current potentiation that each splice variant exhibited after phorbol treatment. For the results here and throughout, the degree of current potentiation is always expressed as a percentage increase from a stabilized baseline current (discussed in Materials and Methods) established before incubation in the PKC-activating agent phorbol ester dibutyrate (PDBu; $20 \mathrm{nM}$, $8 \mathrm{~min})$. The nomenclature shown on the $x$-axis is adopted from Durand et al. (1993) and identifies the particular splice variant with the plotted data. 0 or 1 indicates, respectively, the absence or presence of the alternatively spliced exons in the $5^{\prime}-3^{\prime}$ order N1, C1, C2. Splice variants that only differ
0.016; NR1-000, 84.4\% greater, $p=0.0016$; NR1-100, $52.8 \%$ greater, $p=0.0085$; analysis by Student's $t$ test).

The PKC-mediated potentiation of homomeric NR1 currents has a calcium-sensitive component that is exon specific

The splice variants are generated by the presence or absence of three exons. The effect of a particular exon was determined by grouping all the data for which that exon was present and comparing it with the grouped data from variants lacking the exon (Fig. $3 A, B$ ). The hatched bar for N1 in Figure $3 A$, for example, represents the average potentiation recorded in COS for all splice variants that contain the $\mathrm{N} 1$ exon (i.e., NR1-111, -101 , -110 , and $-100)$. When the analysis is performed in this way, several important observations become apparent. Foremost, the $\mathrm{C} 1$ exon blocks the expression of the higher level of potentiation when recording in calcium solution. This is shown in Figure $3 A$ where the presence of $\mathrm{C} 1$ leads to a significant $31.0 \%$ decrease in the amount of potentiation compared with when the exon is not present (333 \pm $12 \%$ of baseline, $n=134$ vs $483 \pm 17 \%$ of baseline, $n=112 ; p<$ 0.00001 by Student's $t$ test). This phenomenon is completely abolished in BOS (Fig. 3B) where the degree of potentiation for splice variant currents containing the $\mathrm{C} 1$ exon does not differ from the potentiation observed for splice variant currents in which the $\mathrm{C} 1$ exon is absent ( $316 \pm 13 \%$ of baseline vs $314 \pm 15 \%$ of baseline; $p=0.94$, Student's $t$ test). Neither the N1 exon nor the $\mathrm{C} 2$ exon alters the degree of potentiation observed in either of the recording solutions used. This is confirmed by a three-way ANOVA (discussed in Materials and Methods), which indicates that in COS the variance could be explained by $\mathrm{C} 1(p<0.0005)$ and not by any other alternatively spliced exon or by an interaction of these exons.

As discussed above, none of the data representing the presence or absence of exons deviates significantly from the overall mean level of potentiation seen in BOS $(315.0 \pm 9.8 \%$ of the baseline current), indicating that the exon dependence of potentiation is not realized when barium replaces calcium as the major divalent ion in the recording solutions (Fig. 3B). In terms of the magnitude of potentiation seen in COS compared with BOS, the data representing both exon presence and exon absence are significantly reduced, in general, in BOS for all three of the exons. The one exception is the data set representing the NR1-X1X variants, which is not statistically different in COS compared with BOS (333 $\pm 12 \%$ of baseline current vs $316 \pm 13 \%$ of baseline; $p=$ 0.936 , Student's $t$ test). Thus, the C1-containing variants potentiate to the same low level in either calcium or barium solutions, whereas the variants lacking $\mathrm{C} 1$ potentiate to this low level only in the barium solution. Because the higher level of potentiation obtained by the NR1-X0X variants in COS is not expressed in BOS, calcium flux through the receptor itself may be important in activating a process that leads to the higher potentiation. The magnitude of this higher form of potentiation may result from the summing of two events: the calcium-independent lower level of potentiation and the $\mathrm{C} 1$-modulated, calcium-dependent process.

\section{$\leftarrow$}

in their exon composition by the presence or absence of $\mathrm{C} 1$ are plotted adjacent to each other in the figure. Pairwise comparisons made between such variants demonstrate a significant difference, with $\mathrm{C} 1$ presence always giving rise to a lower degree of potentiation $\left({ }^{*} p<0.001\right.$, Student's $t$ test). 
A

\section{BOS}

NR1-OOO
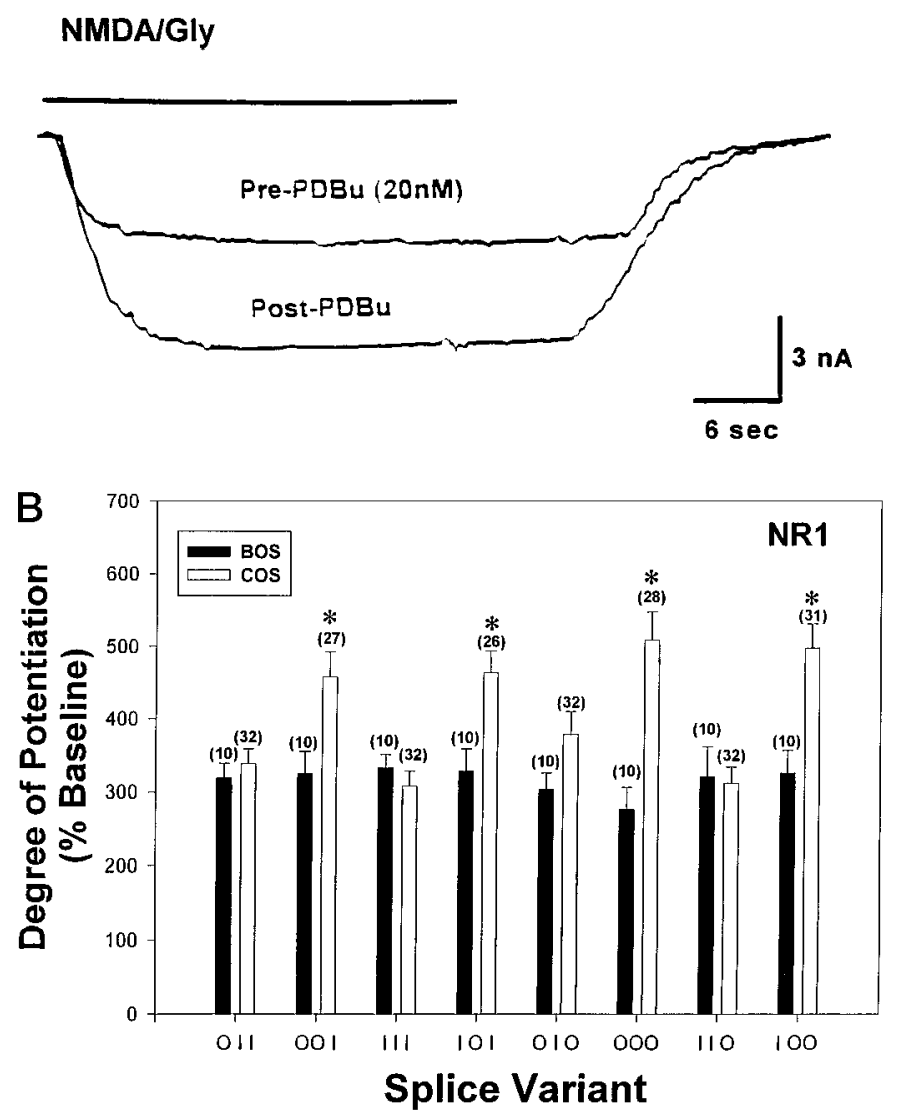

Figure 2. A, Barium replacement solution reduces the degree of phorbolmediated potentiation of currents expressed from homomeric NR1-000 splice variant channels. Essentially, the experiment was performed as in Figure $1 A$, recording in a barium replacement solution $(B O S)$ in which barium replaces all divalents $(2.8 \mathrm{mM})$. Traces are taken before (Pre$P D B u)$ and after (Post-PDBu) an 8 min incubation in PDBu (20 nM). Bars above the traces indicate the time of agonist application. Note that the scale in Figure $1 A$ is approximately seven times larger than shown here, reflecting the lower current sizes obtained in BOS. These particular traces were recorded from different batches of cells. $B, \mathrm{NR} 1-\mathrm{X} 0 \mathrm{X}$ variants yield a significantly higher degree of current potentiation by PDBu when recording in calcium (COS) compared with recordings made in barium (BOS). Each of the eight splice variants were injected into oocytes from the same batch, and the degree of potentiation was determined as outlined in Figure $1 B$. The black bars represent the mean degree of phorbolmediated potentiation \pm SEM found for each of the variants when recording in BOS normalized to the baseline currents. The data set obtained in COS (white bars) is included here from Figure $1 B$ for comparison. The number of oocytes used for each mean is indicated above the appropriate bar. In BOS, the variants do not differ significantly from each other in terms of their modulation, with an average potentiation of $315 \pm 10 \%(n=80)$ over the established baseline currents (analysis by four-way ANOVA). Those variants that lack $\mathrm{C} 1$ demonstrate a significant difference between the data collected in COS versus BOS (*, Student's $t$ test).

\section{The calcium-sensitive component of current} potentiation does not involve the endogenous calciumdependent chloride channels

To determine whether the apparent differences in the degree of potentiation seen in COS compared with BOS are attributable to the involvement of the contaminating $I_{\mathrm{Cl}(\mathrm{Ca})}$ or are instead
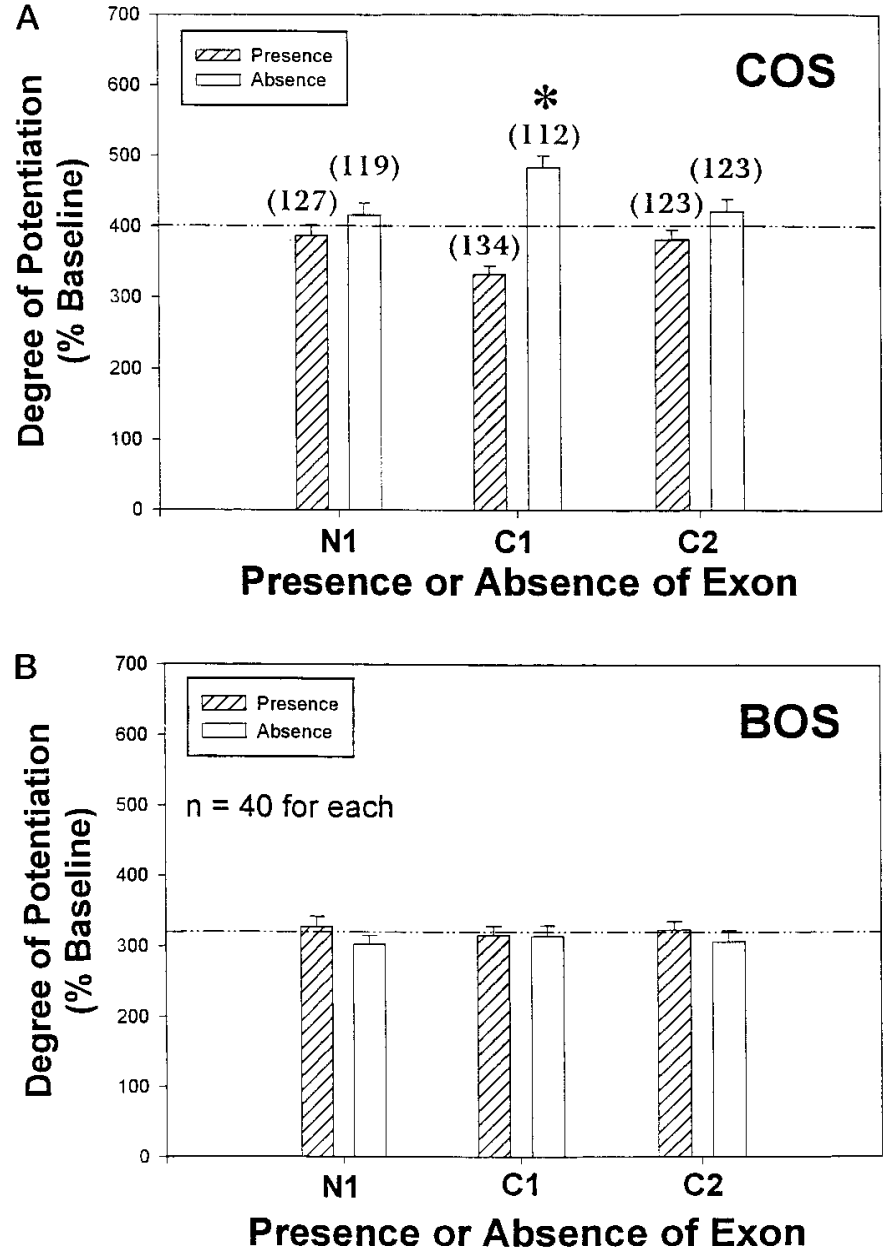

Figure 3. In COS, the $\mathrm{C} 1$ exon is solely responsible for the differences in phorbol potentiation of splice variant currents. $A$, The effect of a particular exon was determined by grouping all the data for which the exon was present (diagonally striped bars) and comparing them with the grouped data for exon absence (open bars). The number above the bars represents the number of cells used to generate the mean value displayed. The overall mean potentiation is $401 \pm 11 \%$ (dashed line). A three-way ANOVA indicates that the variance is explained solely by the $\mathrm{C} 1$ exon $(p<0.0005)$ and not by the $\mathrm{N} 1$ or $\mathrm{C} 2$ exons or by an interaction among the N1, C1, and C2 exons. B, Both the Student's $t$ test and three-way ANOVA indicate that in BOS there is no effect of the alternatively spliced exons on the degree of mean current potentiation. The overall mean potentiation is $315 \pm 10 \%$ (dashed line).

caused by some other $\mathrm{Ca}^{2+}$-dependent mechanism, the current modulation by PKC activation in COS was examined in the presence of NFA, at a concentration $(200 \mu \mathrm{M})$ known to block the endogenous $\mathrm{Cl}^{-}\left(\mathrm{Ca}^{2+}\right)$ channels (Leonard and Kelso, 1990; White and Aylwin, 1990). The experimental protocol used in this study is represented by the bars at the top of the current traces in Figure $4 A$. Agonist solutions containing $200 \mu \mathrm{M}$ NFA were applied followed by an application of agonist alone (i.e., no NFA present) followed by a COS wash (no agonist, no NFA). This protocol compensates for variability in the degree of potentiation observed on a per cell basis. There was no apparent shift in the baseline current from the start of the trial before agonist/NFA application to the final COS wash, indicating that the NFA did not act in some nonspecific way to change the conductance properties of the cell. In all cases (approximately eight cells per variant), the eight splice variants show no significant difference in 
A

\section{NR1-IOI}

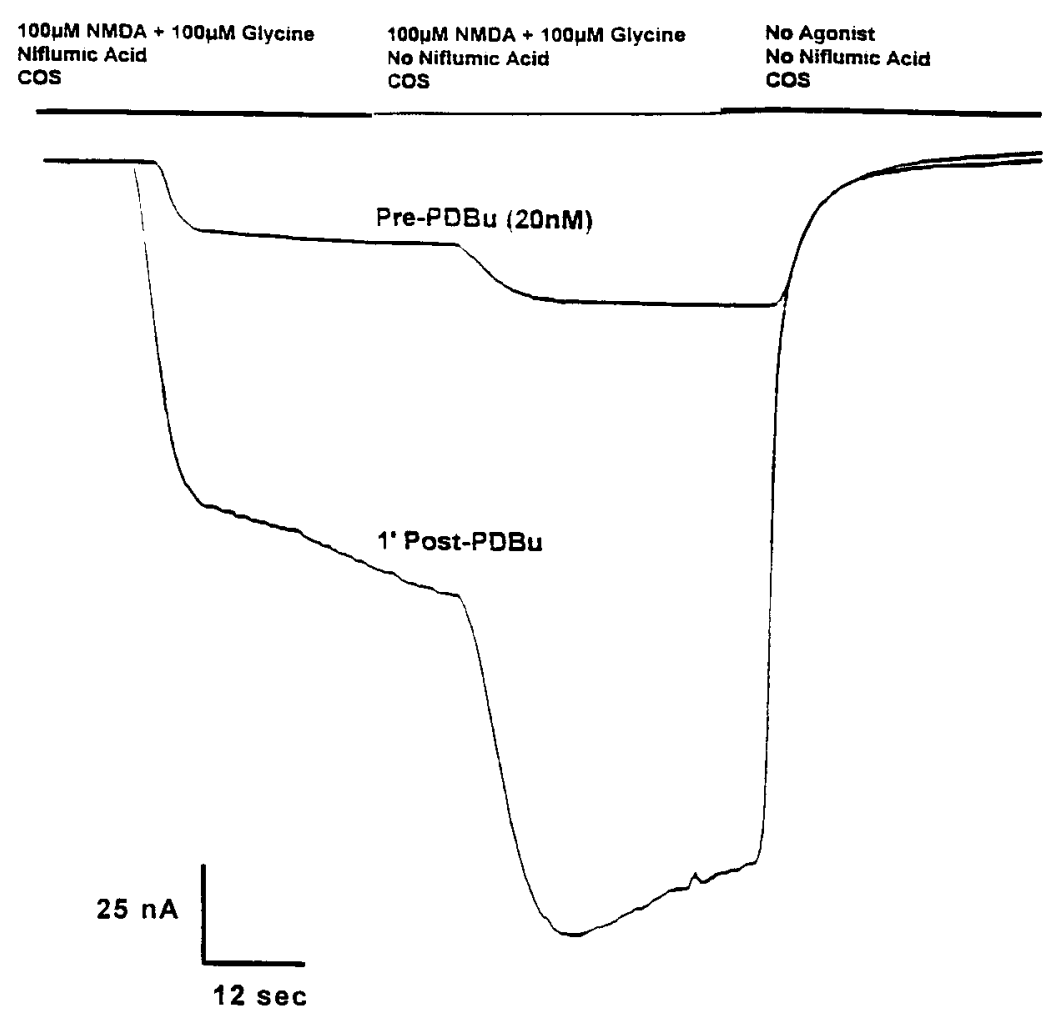

B

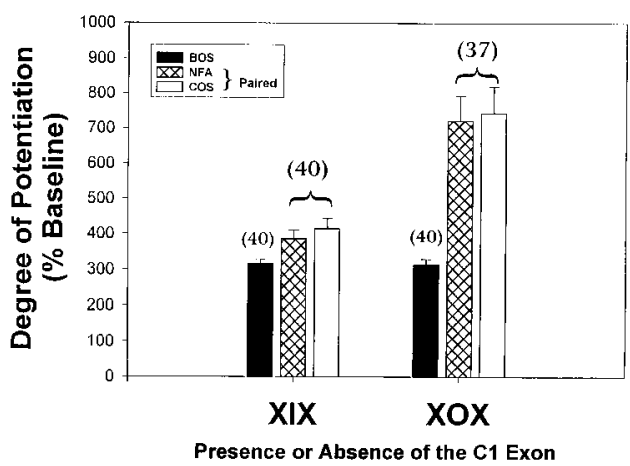

Figure 4. Niflumic acid (NFA), a blocker of $I_{\mathrm{Cl}(\mathrm{Ca})}$, has no effect on the high level of current potentiation by PKC observed in NR1-X0X variants. $A$, The traces represent whole-cell currents recorded at $-80 \mathrm{mV}$ from oocytes injected with NR1-101. The experimental design is represented by the bars at the top of the current traces. Before a trial was run, the test cell was incubated in COS containing $200 \mu \mathrm{M}$ NFA for 1 min. Agonist (100 $\mu \mathrm{M}$ NMDA, $100 \mu \mathrm{M}$ glycine) containing $200 \mu \mathrm{M}$ NFA was applied for $40 \mathrm{sec}$ followed by an application of agonist alone (i.e., no NFA present) for 40 sec followed by a COS wash (no agonist, no NFA). Once a stable baseline was reached (Pre-PDBu), the cell was incubated in $20 \mathrm{~nm}$ PDBu for $8 \mathrm{~min}$. The cell was then washed for $1 \mathrm{~min}$ in COS containing NFA, and currents were evoked in the manner described. Thereafter, currents were elicited every 2 min to generate a time course from which the peak level of current potentiation was determined. In the example shown here, the peak potentiation was reached after the first COS/NFA wash ( $1^{\prime}$ Post-PDBu). The current shown potentiated from 19.8 to $100.1 \mathrm{nA}(506 \%)$ in the presence of NFA and from 33.2 to $172.1 \mathrm{nA}(518 \%)$ after NFA washout. $B$, Experiments were performed on all the splice variants ( $\sim 8$ cells each) as described in $A$. The data were then grouped according to the presence or absence of the $\mathrm{C} 1$ exon, and the mean peak current potentiation was plotted. Numbers in parentheses indicate the number of cells used to generate the data. The open bracket is used to indicate that the NFA data and the COS data are collected from the same cell. The barium data (black bar) are included from the data set in Figure $2 B$ for comparison.

current potentiation after an 8 min incubation in $\mathrm{PDBu}(20 \mathrm{nM})$ in the presence or absence of NFA (data not shown; analysis by Student's $t$ test). All of the splice variants demonstrated a block of the initial peak and a significant reduction in baseline current size in the presence of NFA compared with when NFA was absent, as demonstrated in Figure $4 A$. This reduction of the plateau current, which ranged from $21.9 \pm 2.3 \%$ to $39.8 \pm 4.7 \%$, reflects the contribution made by the $I_{\mathrm{Cl}(\mathrm{Ca})}$ and is an indication that these endogenous channels were actually blocked by the concentration of NFA used.

The grouped data (Fig. 4B) show that the C1-mediated effect on potentiation of currents exists in the presence of NFA (hatched bars) and are comparable to the results obtained in the paired COS-wash data set (open bars). In NFA, the presence of C1 decreased current potentiation by $47 \%$ from the levels observed in splice variants lacking $\mathrm{C} 1$ ( $p<0.0001$, Student's $t$ test), whereas the paired COS data showed a $44 \%$ reduction $(p<$ 0.0001 , Student's $t$ test). For comparison, the barium data shown in Figure $2 B$ are included here (black bars). Currents recorded in the presence of NFA from splice variants that do not contain the
$\mathrm{C} 1$ exon potentiate to a significantly higher degree than they do in BOS, whereas only a minimal difference in potentiation exists between these two conditions when currents are expressed from the C1-containing splice variants. These observations reflect the trends found when the COS and BOS data shown in Figure 3 are compared, indicating that the NFA data parallel the COS data. Thus, the PKC potentiation of splice variant currents is modulated by the $\mathrm{C} 1$ exon through a calcium-dependent mechanism that is not attributable to $I_{\mathrm{Cl}(\mathrm{Ca})}$.

\section{Splice variants coexpressed as heteromers with either NR2A or NR2B exhibit modulation of current potentiation that is dependent on the $\mathrm{C} 1$ exon but not on calcium}

To determine whether the C1-modulated, calcium-dependent process underlying current potentiation in the homomers exists in currents expressed from heteromers, each of the splice variants was coinjected into oocytes from the same batches with cRNA from either NR2A or NR2B, the two members of the NR2 subunit family known to permit the potentiation of currents by 


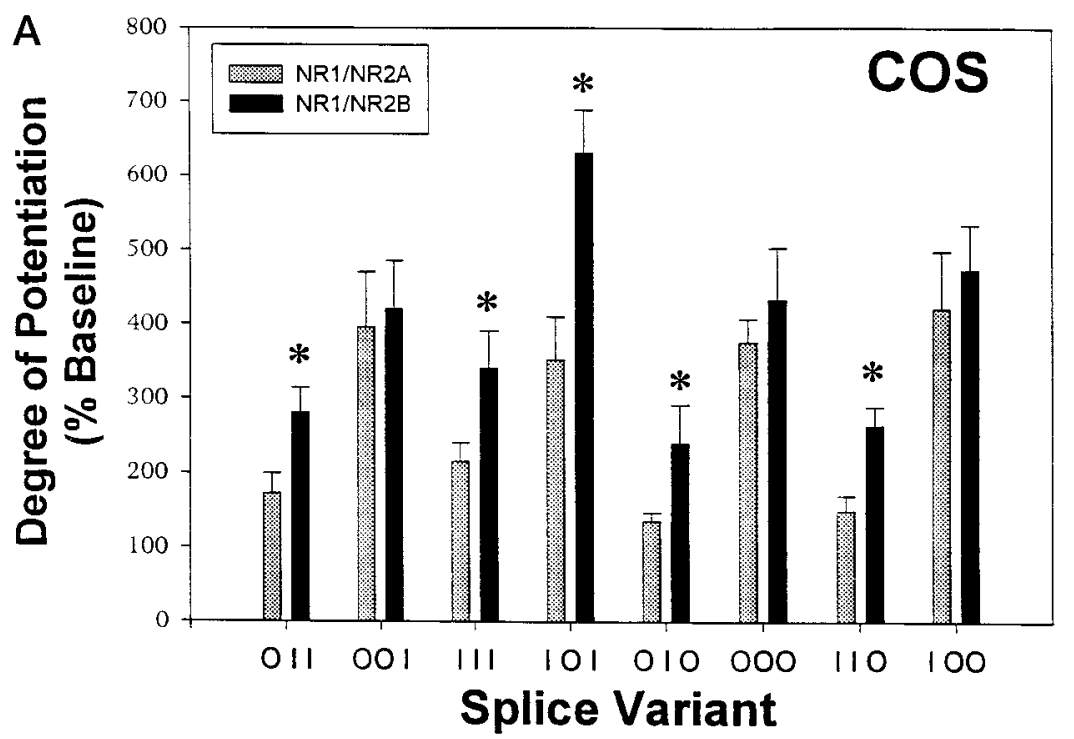

Figure 5. Splice variants show a higher degree of current potentiation when coexpressed with NR2B subunits compared with NR2A subunits as a result of a reduced C1block effect. Each of the splice variants was coinjected in a 1:10 molar ratio with either NR2A or NR2B subunits using oocytes from the same batches. To allow for the best comparison between experiments performed in COS $(A)$ and BOS $(B)$, a particular splice variant was recorded in both solutions within a $2 \mathrm{hr}$ time frame. The data were collected from seven cells for NR2A ( gray bars) and eight cells for NR2B (black bars) using three different frogs in each case. The height of the bar indicates the amount of current potentiation observed after an 8 min exposure to $20 \mu \mathrm{M}$ PDBu. The degree of potentiation was derived by normalizing currents recorded after phorbol treatment to the baseline current recorded before treatment. The asterisks indicate variants that show a significant difference in terms of their potentiation when coexpressed with NR2B compared with NR2A subunits (Student's $t$ test). A comparison between the data in $A$ and $B$ demonstrates that except for NR2A/NR1-000 and NR2B/010, the heteromers show no significant difference in the degree of potentiation in COS compared with BOS (Student's $t$ test).

activators of PKC (Kutsuwada et al., 1992; Yamazaki et al., 1992; Mori et al., 1993). Experiments were performed using protocols similar to those already described for the homomers. The individual pairwise comparisons of heteromers composed of splice variants that either do or do not contain the $\mathrm{C} 1$ exon show that for both NR1/NR2A and NR1/NR2B heteromers, C1 presence always leads to a significantly lower degree of potentiation when recording in calcium solutions (Student's $t$ test) (Fig. 5A, not marked). Thus, heteromeric currents recorded in calcium demonstrate a pattern of potentiation similar to that obtained in homomeric currents. Both the NR2A (gray bars) and NR2B (black bars) heteromers fall into two groups based on their degree of current potentiation: those containing $\mathrm{C} 1$, which are low potentiators (NR1-X1X/NR2A, ranging from 135 to $216 \%$ of baseline; NR1-X1X/NR2B, ranging from 241 to $342 \%$ of baseline), and high potentiators, which do not contain C1 (NR1-X0X/ NR2A, ranging from 353 to $422 \%$ of baseline; NR1-X0X/NR2B, ranging from 420 to $631 \%$ of baseline).

In contrast to the observations in calcium-containing solutions, the levels of potentiation collected for the heteromers in barium solutions do not mirror the levels of potentiation seen when the homomers were recorded in barium. Rather than all potentiating to the same degree, both heteromeric configurations show a wide range of responses (Fig. $5 B$ ). The data shown in Figure $5 A, B$ indicate that for each of the individual heteromers the current potentiation observed in BOS does not differ significantly from that observed in COS ( $p>0.4$; Student's $t$ test). There is one exception to this general trend for each of the NR2 subunits, NR1-000/NR2A and NR1-010/NR2B, which do demonstrate a difference in potentiation for the two conditions $(p<0.01$ and $p<0.005$, respectively; Student's $t$ test).

On the basis of the observation above, it can be predicted that the data collected in barium should also demonstrate a $\mathrm{C} 1$ modulated effect on the degree of potentiation similar to the results obtained when recording in calcium solutions. However, an examination of individual pairwise comparisons of splice variants that either do or do not contain the $\mathrm{C} 1$ exon shows that for both NR2A and NR2B heteromers, only the NR1-110 and NR1-100 pair demonstrates a significant difference between each other in terms of their potentiation (Student's $t$ test) (Fig. $5 B$, not marked). This contrasts with the results obtained when recording in calcium solutions where, in every case, heteromers containing 
a particular NR1-X1X variant demonstrate a significantly lower level of potentiation than the appropriately paired NR1-X0X heteromer lacking the $\mathrm{C} 1$ exon (Fig. $5 A$ ). These results suggest that although not entirely absent, the $\mathrm{C} 1$ modulation of potentiation in the heteromers is not as robust in barium as it is in calcium.

\section{The C1-mediated decrease in potentiation is weaker in NR2B heteromers compared with their NR2A counterparts}

In calcium, individual C1-containing NR2B heteromers (NR1$\mathrm{X} 1 \mathrm{X} / \mathrm{NR} 2 \mathrm{~B}$ ) potentiate to a significantly greater degree than do their NR2A counterparts in every case (Student's $t$ test) (Fig. 5A, asterisks). In contrast, the NR1-X0X/NR2B heteromers all potentiate to the same degree as their paired NR1-X0X/NR2A heteromers. The exception is NR1-101/NR2B, which does demonstrate a significant difference compared with its paired NR1101/NR2A heteromer (Fig. 5A, asterisk). The overall trend, however, suggests that when recording in calcium, the NR2A and NR2B heteromers potentiate to the same level by some process that is blocked by the $\mathrm{C} 1$ exon to differing degrees. The fact that the presence of $\mathrm{C} 1$ does not reduce the potentiation as greatly in the NR2B heteromers as in the NR2A heteromers implies that the $\mathrm{C} 1$-mediated block to the process is weaker in the NR2B heteromers. Similar results are found when recording in barium solutions, which show that, as in calcium, the individual NR1$\mathrm{X} 1 \mathrm{X} / \mathrm{NR} 2 \mathrm{~B}$ heteromers all potentiate to a significantly higher level than their paired NR1-X1X/NR2A heteromers (Fig. 5B, asterisks). These results suggest that the structural differences known to exist between these two NR2 subunits, perhaps in their divergent $\mathrm{C}$-terminal regions, are responsible for differential effects of the C1-mediated modulation.

\section{Grouped data analysis reveals the importance of NR1 exons in the potentiation of NR2A and NR2B heteromers}

Analysis of the grouped data allows for a closer examination of the trends demonstrated above for the individual variants. As is the case with the homomeric currents, Student's $t$ test indicates that neither exon N1 (NR2A, $p=0.739$; NR2B, $p=0.060)$ nor exon $\mathrm{C} 2(\mathrm{NR} 2 \mathrm{~A}, p=0.760$; NR2B, $p=0.143)$ participates in the PKC-stimulated potentiation of heteromeric currents (Figs. $6 A, C)$ when recording in calcium solutions. The same analysis performed on the data collected in barium solutions (Figs. 6B,D) shows a similar trend with neither the $\mathrm{N} 1$ exon $(\mathrm{NR} 2 \mathrm{~A}, p=0.581$; $\mathrm{NR} 2 \mathrm{~B}, p=0.849)$ nor the $\mathrm{C} 2$ exon (NR2A, $p=0.825$; NR2B, $p=0.482)$ participating in the potentiation. The $\mathrm{C} 1$ exon, on the other hand, shows a significant effect on the degree of potentiation for the NR2A and NR2B heteromers in both calcium and barium solutions that is confirmed by a four-way ANOVA (COS: NR2A, $p<0.001$; NR2B, $p<0.001$; BOS: NR2A, $p<0.05$; $\mathrm{NR} 2 \mathrm{~B}, p<0.005)$.

When expressed as a heteromer with either of the two NR2 subunits, the $\mathrm{C} 1$ exon of the NR1 subunit plays a role in potentiation similar to its role in the potentiation of homomeric receptor currents: some process mediated in the absence of the $\mathrm{C} 1$ exon is responsible for attaining the higher level of potentiation. In the presence of $\mathrm{C} 1$, this process is blocked (C1-block), resulting in a lower form of potentiation. In the heteromers, the process mediating the C1-block shows subunit dependence in terms of effectiveness and calcium sensitivity. For NR1/NR2A heteromers, C1 presence exhibits a $57 \%$ decrease (Fig. 6 A, asterisk) from the level attained in the absence of the exon $(168 \pm 12 \%, n=28$ vs $387 \pm$
$30 \%$ of baseline current, $n=28 ; p<0.001$, Student's $t$ test). This decrease in potentiation by $\mathrm{C} 1$ presence is larger than the $43 \%$ drop (Fig. 6C, asterisk) seen for the NR1/NR2B heteromers (282 $\pm 17 \%, n=32$ vs $490 \pm 32 \%$ of baseline currents, $n=32$; $p<0.001$, Student's $t$ test). The $\mathrm{C} 1$ effect demonstrated in the heteromers in both cases is larger than the $31 \%$ decrease already noted for the homomers ( $333 \pm 12 \%$ baseline, $n=134$ vs $483 \pm$ $17 \%$ baseline, $n=112$ ). Thus, in calcium recording solutions, the subunit composition of channels may be ranked in the following order according to the strength of the C1-block they permit: $\mathrm{NR} 1 / \mathrm{NR} 2 \mathrm{~A}>\mathrm{NR} 1 / \mathrm{NR} 2 \mathrm{~B}>\mathrm{NR} 1$.

The grouped data from recordings in barium solutions show that, similar to the results obtained in calcium solutions, $\mathrm{C} 1$ is the sole exon involved in the modulation of the current enhancement by phorbol for both the NR2A and NR2B heteromers (Fig. $6 B, D)$. Specifically, the NR1-X1X/NR2A heteromers potentiate to a level that represents a $46 \%$ reduction (Fig. $6 B$, asterisk) in the level of potentiation attained by the NR1-X0X/NR2A heteromers $(175 \pm 20 \%$ vs $317 \pm 36 \%$ of baseline current; $p<0.001$, Student's $t$ test). The potentiation of the NR1/NR2B heteromeric currents is significantly reduced by $28 \%$ when $\mathrm{C} 1$ is present compared with the potentiation seen in the absence of the exon $(361 \pm 23.2 \%$ vs $502 \pm 32 \%$ of baseline current; $p<0.001$; marked by asterisk in Fig. 6D). Again, the NR2A subunit is shown to have a larger C1-mediated decrease in current potentiation compared with heteromers composed of the NR2B subunit that demonstrate a considerably smaller C1-block to potentiation. Thus in both calcium and barium solutions, there exists a subunit dependency to the $\mathrm{C} 1$ modulation, suggesting that the region of modulation may be restricted physically to the divergent C-terminal domains of the two NR2 subunits.

Homomeric currents demonstrate a high form of potentiation that occurs only in the absence of the $\mathrm{C} 1$ exon and not in the presence of barium. Comparison of the data shown in Figure $6 \mathrm{~A}$ with that in $6 B$ (open bars) shows that the potentiation observed for NR1-X0X/NR2A heteromers in COS does not differ from the potentiation obtained in BOS $(387 \pm 30 \%$ of baseline currents, $n=28$ vs $317 \pm 36 \%$ of baseline, $n=28 ; p=0.140$, Student's $t$ test). The same is true for the NR1-X0X/NR2B heteromers (Fig. 6C,D, open bars), which potentiate to the same degree in COS or BOS (490 $\pm 32 \%$ of baseline currents vs $502 \pm$ $32 \%$ of baseline; $p=0.793$ ). Thus, like the homomers, the process leading to the higher level of potentiation occurs in the absence of the $\mathrm{C} 1$ exon. However, in the NR2A and NR2B heteromers, this process is no longer calcium dependent, yielding similar potentiation in either calcium or barium solutions.

The process mediating the $\mathrm{C} 1$-block in the NR1-X1X/NR2A heteromers is equally effective in calcium or barium solutions $(168 \pm 12 \%$ of baseline currents, $n=28$ vs $175 \pm 20 \%$ of baseline; $p=0.79$, Student's $t$ test), suggesting that the C1-block is not calcium-sensitive in the NR2A heteromers. However, NR1$\mathrm{X} 1 \mathrm{X} / \mathrm{NR} 2 \mathrm{~B}$ heteromers potentiate $28 \%$ higher in barium solutions compared with solutions containing calcium $(361 \pm 23 \%$ of baseline currents vs $282 \pm 17 \%$ of baseline; $p=0.007)$. Thus, in NR2B heteromers, the C1-block to the higher level of potentiation is less effective than the block demonstrated in the NR2A heteromers and shows a degree of calcium sensitivity to the block itself.

Collectively, the data above may support the idea that barium is able to substitute for some calcium-dependent component in the modulation of current potentiation by PKC, but it does so with less efficacy. In NR2A heteromers, barium may be less 

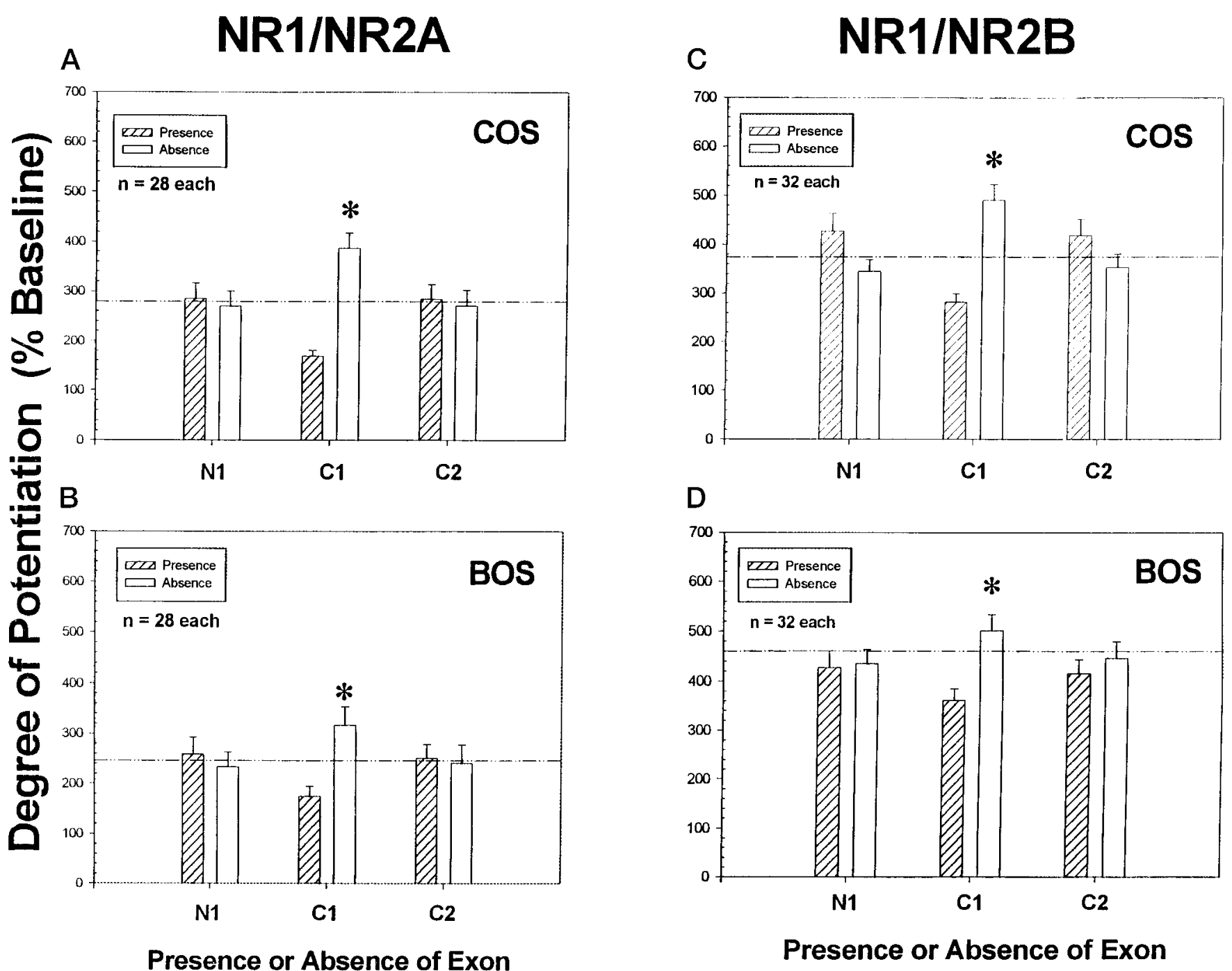

Figure 6. The C1-block to higher potentiation is reduced in splice variants coexpressed with NR2B subunits compared with those expressed with NR2A subunits. The results shown represent a summary of the data collected in Figure 5 grouped by exon presence (diagonally striped bars) or absence (open bars). The particular exon the data represent is given on the $x$-axis. $A, B$, Exon significance in the degree of heteromeric NR2A potentiation. Each bar represents a summary of data from 28 cells. $A$, Summary of the data collected in calcium-containing solutions $(C O S)$. Only the $\mathrm{C} 1$ exon shows a significant effect on the degree of potentiation, with the presence exhibiting a 57\% decrease ( ${ }^{*} p<0.001$, Student's $t$ test) from the level attained in the absence of the exon. The mean potentiation is $278 \pm 21.7 \mathrm{nA}$ (dashed line). B, Summary of the data collected in barium-containing solutions (BOS). The NR1/NR2A heteromers in which $\mathrm{C} 1$ is present potentiated $46 \%$ lower $\left({ }^{*} p<0.001\right.$, Student's $t$ test $)$ than the level of enhancement found in the C1-containing heteromers. As in COS, neither the N1 exon $(p=0.581)$ nor the $\mathrm{C} 2$ exon $(p=0.825)$ is involved in the current potentiation. The mean potentiation is $245.8 \pm 22.7 \mathrm{nA}$ (dashed line). $C, D$, Exon significance in the degree of heteromeric NR2B potentiation. Each bar represents a summary of data from 32 cells. $C$, In COS, C1 presence leads to a significant $43 \%$ decrease in potentiation $\left({ }^{*} p<0.001\right.$, Student's $t$ test $)$ compared with the potentiation seen in heteromers where the $\mathrm{C} 1$ exon is absent. As for the NR2A heteromers, neither exon $\mathrm{N} 1(p=0.060)$ nor exon $\mathrm{C} 2(p=0.143)$ participates in the PKC-stimulated potentiation of heteromeric currents (Student's $t$ test). The mean potentiation is $386.0 \pm 22.2 \mathrm{nA}$ (dashed line). $D$, In BOS, the presence of the $\mathrm{C} 1$ exon leads to a significant $28 \%$ reduction in potentiation $\left({ }^{*} p<0.001\right.$, Student's $t$ test) compared with heteromers that did not contain the $\mathrm{C} 1$ exon. Neither the $\mathrm{N} 1$ exon $(p=0.849)$ nor the $\mathrm{C} 2$ exon $(p=0.482)$ is involved in the current potentiation. The mean current potentiation is $432 \pm 21 \%$ of baseline (dashed line).

effective than calcium in attaining the higher level of potentiation, whereas in NR2B heteromers, barium may be less effective than calcium in mediating the C1-block to the higher form of potentiation.

\section{The degree of potentiation is not dependent on the size of the baseline current}

An examination of NR1 currents generated in COS and BOS before treatment with phorbol (i.e., baseline currents) shows that in both conditions there is an exon dependence to the size of the current. The most robust effect is seen for the N1 exon where analysis by $t$ test indicates that N1 presence leads to a significant increase in current size in both COS $(52.3 \%, p<0.001)$ and BOS $(116.4 \%, p<0.001)$. The $\mathrm{C} 1$ exon also affects current size, depending on the divalent ion used in the recording solutions. In $\mathrm{COS}$, the presence of $\mathrm{C} 1$ leads to a significant increase in the current size $(26.8 \%, p=0.01)$, whereas in BOS, C1 presence leads to a much higher increase $(106.1 \%, p<0.001)$. The presence of the $\mathrm{C} 2$ exon demonstrates the least effect on baseline currents, showing a significant decrease in COS only $(18.9 \%, p=$ 
0.02). A three-way ANOVA performed on the COS data in which current size was the dependent variable and the presence or absence of exons were the variables under consideration for effects confirms the trend shown above.

A possible explanation for the differences in potentiation observed between the NR1 splice variant homomers may be that the variants displaying smaller baseline currents potentiate to a different degree (greater or smaller) than those displaying larger currents. However, the trends discussed above in terms of exon control of homomeric current potentiation indicate that this is not the case. For example, the presence of the N1 exon that produces a larger current size compared with when N1 is absent shows no effect on the degree of potentiation for any of the individual splice variants in either COS or BOS.

To further examine this issue, the mean baseline current for each NR1 variant was plotted against the corresponding mean degree of potentiation for the data collected in calcium and barium solutions. In COS, the effects of the N1 and $\mathrm{C} 1$ exons are clearly evident, with $\mathrm{N} 1$ mainly controlling current size and $\mathrm{C} 1$ controlling potentiation (Fig. $7 A$ ). The graph can be divided into quadrants essentially based on exon function: low and high potentiators depending on the presence or absence of the $\mathrm{C} 1$ exon and variants with high or low baseline currents depending on the presence or absence of the N1 exon. Thus, NR1-000 is in the top left quadrant, whereas NR1-111 is in the bottom right quadrant. Visual inspection of the figure indicates that current size does not predict the degree of potentiation.

In BOS, because $\mathrm{C} 1$ no longer has an effect on potentiation, the data points do not separate in terms of this variable (Fig. 7B). However, $\mathrm{C} 1$ presence does lead to a greater baseline current size and acts in combination with the effect of $\mathrm{N} 1$ on current size such that variants separate out into three clusters based on current size, independent of the degree of potentiation: those that contain both cluster at the right end of the graph, those that contain neither group at the left end, and variants containing a mixture of these cluster in the middle. Again, the degree of potentiation cannot be predicted on the basis of baseline current size.

In NR2A and NR2B heteromers, regression analysis reveals that the degree of current potentiation is not correlated with the size of the initial baseline current, eliminating the possibility that the differences in the degree of potentiation exhibited by the splice variants are a function of their mean current size (data not shown).

\section{DISCUSSION}

NR1 homomeric currents expressed from splice variant clones in Xenopus oocytes potentiate in a range $\sim 300-500 \%$ over their initial baseline values after exposure to the PKC-activating agent phorbol ester when recording in calcium-containing solutions. All recording solutions omitted magnesium because a change in sensitivity to inhibition by magnesium ions plays no part in the PKC potentiation of recombinant NMDAR currents expressed in oocytes (Wagner and Leonard, 1996). This range is in marked contrast to the $\sim 300-2000 \%$ range of potentiation reported elsewhere (Durand et al., 1992, 1993; Yamazaki et al., 1992; Yamakura et al., 1993; Zheng et al., 1997). The variants divide into two groups: low responders, which potentiate between 310 and $380 \%$ of their baseline currents, and high responders, which range from 460 to $510 \%$. This physiological property correlates solely with the presence or absence of the $\mathrm{C} 1$ exon, where the presence of the exon leads to a $31 \%$ decrease in potentiation $(p<0.0005$, three-way ANOVA).
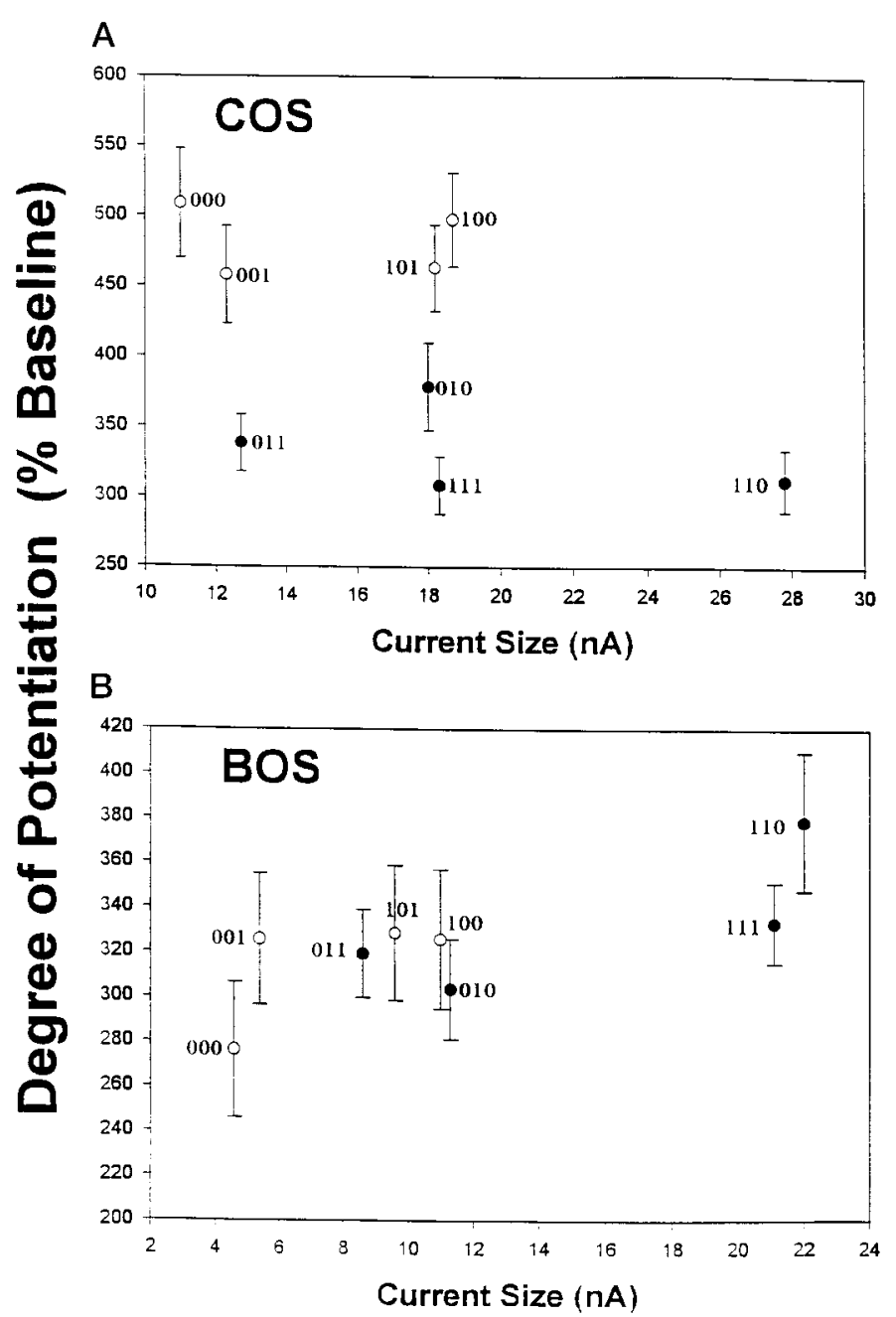

Figure 7. In barium and calcium, mean baseline current size does not predict the mean degree of PKC-mediated current potentiation. The mean values for baseline current size and degree of potentiation for each of the splice variants expressed as homomers are plotted against one another to clarify the relationship between these two variables for the overall data set. $A$ shows the relationship when recording in calcium solutions, whereas $B$ summarizes the data collected in barium. Note how the presence or absence of $\mathrm{N} 1$ predicts current size in both $\operatorname{COS}(A)$ and BOS $(B)$, whereas $\mathrm{C} 1$ presence or absence dictates the degree of potentiation in COS only. Open circles represent variants that do not contain $\mathrm{C} 1$, and the filled circles represent those that do. Error bars are \pm SEM.

Neither the N1 nor C2 exons participate in the differential potentiation either individually or as the result of an interaction among the N1, C1, and $\mathrm{C} 2$ exons (Fig. $3 A$ ). Thus, the finding that $\mathrm{N} 1$ causes an approximately threefold increase in the degree of potentiation observed over those variants not containing the N1 exon and that exon $\mathrm{C} 2$ presence alone leads to a significant decrease in potentiation (Durand et al., 1993; Zheng et al., 1997) is not supported by the experiments performed here. The argument that the N1 exon allows greater potentiation as a result of greater calcium influx (Zheng et al., 1997) also is not supported, because no correlation is found between current size and degree of potentiation (Fig. 7). This study, then, refines the region of positive modulation critical to NMDAR function to a 37 residue domain of the NR1 C-terminal.

When barium replaces external calcium, the additional potentiation seen with clones lacking $\mathrm{C} 1$ is abolished, and currents 
from all splice variants potentiate at the lower level: $\sim 315 \%$ of baseline. A rapid calcium amplification has been suggested to account for this difference (Zheng et al., 1997). Activation of the endogenous calcium-dependent chloride conductance in oocytes $\left(I_{\mathrm{Cl}(\mathrm{Ca})}\right)$ is responsible for the majority of the current amplification seen when switching from barium to calcium solutions (Leonard and Kelso, 1990). Niflumic acid greatly reduces plateau currents by blocking $I_{\mathrm{Cl}(\mathrm{Ca})}$ (Fig. $4 A$ ) yet has no effect on the degree of PKC potentiation of NR1 splice variant currents. Thus, a calcium-sensitive process does underlie the PKC-mediated potentiation, but this process is independent of the simultaneous major current amplification that results in an initial inward peak $\left(I_{\mathrm{Cl}(\mathrm{Ca})}\right)$.

A simple model, therefore, emerges for the modulation of PKC-mediated potentiation as it occurs in homomeric receptors: in the absence of the $\mathrm{C} 1$ exon, a calcium-sensitive process yields the higher level of potentiation. When recording in barium, this calcium-dependent process is blocked, and currents only reach the low level of potentiation.

There are several reasons that may account for why the potentiation of the splice variant currents reported here differs quantitatively and qualitatively from previous studies. Studies demonstrating an effect of the N1 exon on potentiation were recorded in solutions at pH 7.2 (Durand et al., 1993; Zheng et al., 1997) compared with $\mathrm{pH} 7.5$ used in the present study. NMDAR currents are known to be chronically inhibited at physiological $\mathrm{pH}$ (Tang et al., 1990; Saybasili, 1998), with an $\mathrm{IC}_{50}$ of $\mathrm{pH} 7.3$ (Traynelis and Cull-Candy, 1991; Traynelis et al., 1995). If the mechanism of potentiation involves a change in the effectiveness of protons to inhibit the receptor, then $\mathrm{pH}$ may play a critical role. Alternatively, the apparent N1 effect may be attributable to the limited set of splice variants examined previously.

Other discrepancies between the results presented here and those of others may be related to procedural differences. A novel analytical approach by a four-way ANOVA (described in Materials and Methods), in which the variation in individual batches of frog oocytes could be removed from the data set, allowed for data interpretation without contamination by these potential artifacts.

As for the homomers, the modulation of potentiation in the heteromers is solely under the control of the $\mathrm{C} 1$ exon and does not involve the participation of the $\mathrm{N} 1$ or $\mathrm{C} 2$ exons or an interaction among exons (Fig. 6A-D), with the NR2B heteromers demonstrating an overall greater degree of potentiation $(386 \pm$ $22 \%$ vs $278 \pm 22 \%$ for NR2A heteromers). This conflicts with the only previous attempt to characterize the splice variants as heteromers, which shows a positive effect on potentiation by the N1 exon. However, the focus of that study was solely on three splice variants expressed as NR2A heteromers (Zheng et al., 1997). Critically, the results presented here demonstrate a control in the effectiveness of the $\mathrm{C} 1$ exon to block the higher level of potentiation by the heteromeric subunit: in every case, NR1/NR2A heteromers containing the $\mathrm{C} 1$ exon potentiate to a significantly lower degree than the corresponding NR1/NR2B heteromers (Fig. $5 A, B$ ). As a result, the ability of the $\mathrm{C} 1$ exon to block the higher form of PKC potentiation is less prominent in currents expressed from receptors containing the NR2B subunit compared with those containing the NR2A subunit (43 vs $56 \%$ decrease, $p<0.05$ ) (Fig. 6A,C).

Several important signaling molecules (Ehlers et al., 1996; Krupp et al., 1996; Tingley et al., 1997) and structural proteins, including neurofilaments and the novel element yotiao, both of which may be involved in linking the NMDAR to the actin cytoskeleton (Ehlers et al., 1998; Lin et al., 1998), associate with the $\mathrm{C} 1$ exon. The interaction of the moieties associated with $\mathrm{C} 1$ may underlie the events leading to current potentiation by PKC. Activation of PKC leads to phosphorylation of serine residues in C1 (Tingley et al., 1993, 1997) that disrupts calcium/calmodulin (CaM) binding on the receptor (Hisatsune et al., 1997). At elevated levels of both calcium and $\mathrm{CaM}, \alpha$-actinin-2, which regulates NMDAR attachment to actin (Wyszynski et al., 1998), is out-competed for binding by $\mathrm{CaM}$ at a site 20 residues upstream of C1 (Wyszynski et al., 1997). Intriguingly, the same mutations in $\mathrm{C} 1$ that prevent the PKC-mediated uncoupling of the receptor from the cytoskeleton (Ehlers et al., 1995; Tingley et al., 1997) also prevent the C1-block to higher potentiation (Bennett et al., 1997). Conceivably, the downstream effects of CaM release from $\mathrm{C} 1$ by $\mathrm{PKC}$ perhaps may be responsible for the C1-block, possibly by acting through a cytoskeletal mechanism.

NR2B contains an $\alpha$-actinin-2 binding domain in the $\mathrm{C}$ terminus, whereas the NR2A subunit was not found to bind this molecule (Paoletti and Ascher, 1994; Wyszynski et al., 1997). The effectiveness of the C1-block therefore is inversely correlated with the number of $\alpha$-actinin- 2 molecules potentially associated with the receptor and perhaps the degree of interaction between the receptor and the actin cytoskeleton. This is particularly intriguing because in addition to differential patterns of NR2A and NR2B subunit expression, $\alpha$-actinin-2 shows developmental and regional differences of expression in the rat brain (Wyszynski et al., 1998) and thus may allow for synapse-specific modulation of plastic events.

Homomeric currents are relatively small, suggesting that the calcium-sensitive processes involved in the potentiation of variants that lack $\mathrm{C} 1$ are proximal to the channel pore. Many of the proteins discussed above ( $\alpha$-actinin-2, actin, CaM, PKC), are regulated by calcium (Ehlers et al., 1996; Wyszynski et al., 1997) and bind the supramolecular complex associated with the NMDAR. Thus these proteins are in a position to mediate the higher form of potentiation. Furthermore, barium does not substitute efficiently for calcium even at micromolar concentrations (Chao et al., 1984; Richardt et al., 1986; Gupta et al., 1990) and may account for why the higher form of potentiation is not attained in homomeric currents recorded in barium solutions.

In contrast to the homomers, heteromers demonstrate the high level of potentiation in barium. Assuming a conserved mechanism of potentiation, these conflicting results may be resolved if barium, at greater than micromolar concentration, can substitute at key calcium-sensitive processes. Heteromeric currents are 25-50 times larger than homomeric currents. Additionally, barium is not sequestered as efficiently as calcium (Sihra et al., 1993). If heteromers form clusters of channels producing large local currents, then the internal concentration of barium may be sufficiently high to activate the calcium-dependent processes involved in the C1-mediated effect. A similar mechanism has been proposed to underlie the inefficiency of barium substitution for calcium in NMDAR inactivation (Krupp et al., 1996). An intriguing observation presented here is that calcium may have differential effects in the potentiation of the heteromers, with the NR2A heteromers demonstrating a higher calcium sensitivity in attaining the higher level of potentiation, whereas in NR2B heteromers, the $\mathrm{C} 1$-block to the higher form of potentiation itself may be mediated by calcium (Fig. $6 A-D$ ).

The physiological relevance of the findings presented here is supported by anatomical data that indicate the segregation of neuronal populations based on the presence or absence of the $\mathrm{C} 1$ 
exon (Sheng et al., 1994; Laurie et al., 1995; Zhong et al., 1995; Zukin and Bennett, 1995). Furthermore, the receptor subunit composition and distribution pattern is developmentally regulated in rat brain (Watanabe et al., 1993; Monyer et al., 1994), with NR2A subunits incorporating into functional NR1/NR2A heteromers and NR1/NR2A/NR2B heterotrimers in the neocortex and striatum only after postnatal day 7 (Sheng et al., 1994; Zhong et al., 1995; Portera-Cailliau et al., 1996). Before this time, NR2B subunits dominate heteromeric NMDAR complexes, and their presence is thought to be important during developmental plasticity (Monyer et al., 1994; Portera-Cailliau et al., 1996; Sircar et al., 1998). The increased incorporation of the NR2A subunit into receptor complexes during development of the forebrain predicts a greater C1-block to current potentiation and suggests that different sensitivities of the receptor to PKC activity may be required at different stages of synaptogenesis. The developmentally regulated incorporation of NR2A subunits into heteromeric NMDAR complexes has other functional consequences such as the decrease in ifenprodil sensitivity (Williams et al., 1993; Zhong et al., 1995) and the faster kinetics of NMDAR EPSCs (Monyer et al., 1994; Flint et al., 1997). In combination with other receptor properties that change during development, the decrease in sensitivity to $\mathrm{PKC}$ as a consequence of NR2A incorporation into NMDARs may contribute to a developmental loss in cortical plasticity.

The results from this study represent the first complete characterization of the PKC-mediated potentiation of the NMDAR splice variants expressed not only as homomers but also as heteromeric assemblies, which are thought to be the more physiologically relevant form. A clear role for the $\mathrm{C} 1$ exon in mediating the potentiation is shown in all assemblies in which the presence of the exon leads to a lower form of potentiation. This $\mathrm{C} 1$ effect in turn is modulated by the heteromeric assembly, with NR2A subunits conveying a greater sensitivity to the effect than NR2B subunits. This has widespread implications in the processing of synaptic events because the control of response can be regulated at the transcriptional level.

\section{REFERENCES}

Barish ME (1983) A transient calcium-dependent chloride current in the immature Xenopus oocyte. J Physiol (Lond) 342:309-325.

Bennett MVL, Zhang L, Zheng X, Zukin RS (1997) Role of the carboxy terminal domain of the NMDA receptor in PKC potentiation. Soc Neurosci Abstr 23:945.

Bliss TV P, Collingridge GL (1993) A synaptic model of memory: longterm potentiation in the hippocampus. Nature 361:31-39.

Boton R, Dascal N, Gillo B, Lass Y (1989) Two calcium-activated chloride conductances in Xenopus laevis oocytes permeabilized with the ionophore A23187. J Physiol (Lond) 408:511-534.

Chao S-H, Suzuki Y, Zysk JR, Cheung W-Y (1984) Activation of calmodulin by various metal cations as a function of ionic radius. Mol Pharmacol 26:75-82.

Chen L, Huang L-YM (1991) Sustained potentiation of NMDA receptor-mediated glutamate responses through activation of protein kinase $C$ by a $\mu$ opioid. Neuron 7:319-326.

Chen L, Huang L-YM (1992) Protein kinase C reduces $\mathrm{Mg}^{2+}$ block of NMDA-receptor channels as a mechanism of modulation. Nature 356:521-523.

Collingridge GL, Singer W (1990) Excitatory amino acid receptors and synaptic plasticity. Trends Pharmacol Sci 11:290-296.

Constantine-Paton M, Cline HT, Debski E (1990) Patterned activity, synaptic convergence and the NMDA receptor in developing visual pathways. Annu Rev Neurosci 13:129-154.

Drummond DR, Armstrong J, Colman A (1985) The effect of capping and polyadenylation on the stability, movement and translation of synthetic messenger RNAs in Xenopus oocytes. Nucleic Acids Res 13:7375-7394.
Durand GM, Gregor P, Zheng X, Bennett MVL, Uhl GR, Zukin RS (1992) Cloning of an apparent splice variant of the rat $N$-methyl-Daspartate receptor NMDAR1 with altered sensitivity to polyamines and activators of protein kinase C. Proc Natl Acad Sci USA 89:9359-9363.

Durand GM, Bennett MVL, Zukin RS (1993) Splice variants of the $N$-methyl-D-aspartate receptor NR1 identify domains involved in regulation by polyamines and protein kinase C. Proc Natl Acad Sci USA 90:6731-6735.

Ehlers MD, Tingley WG, Huganir RL (1995) Regulated subcellular distribution of the NR1 subunit of the NMDA receptor. Science 269:1734-1737.

Ehlers MD, Zhang S, Bernhardt JP, Huganir RL (1996) Inactivation of NMDA receptors by direct interaction of calmodulin with the NR1 subunit. Cell 84:745-755.

Ehlers MD, Fung ET, O’Brien RJ, Huganir RL (1998) Splice variantspecific interaction of the NMDA receptor subunit NR1 with neuronal intermediate filaments. J Neurosci 18:720-730.

Flint AC, Maisch US, Weishaupt JH, Kriegstein AR, Monyer H (1997) NR2A subunit expression shortens NMDA receptor synaptic currents in developing neocortex. J Neurosci 17:2469-2476.

Gerber G, Kangrga I, Ryu PD, Larew JSA, Randic M (1989) Multiple effects of phorbol esters in the rat spinal dorsal horn. J Neurosci 9:3606-3617.

Gupta RC, Khandelwal RL, Sulakhe PV (1990) Divalent cation effects on calcineurin phosphatase: differential involvement of hydrophobic and metal binding domains in the regulation of the enzyme activity. Mol Cell Biochem 97:53-66.

Hall RA, Soderling TR (1997) Differential surface expression and phosphorylation of the $N$-methyl-D-aspartate receptor subunits NR1 and NR2 in cultured hippocampal neurons. J Biol Chem 272:4135-4140.

Hisatsune C, Umemori H, Inoue T, Michikawa T, Kohda K, Mikoshiba K, Yamamoto T (1997) Phosphorylation-dependent regulation of $N$-methyl-D-aspartate receptors by calmodulin. J Biol Chem 272:20805-20810.

Hollmann M, Boulter J, Maron C, Beasley L, Sullivan J, Pecht G, Heinemann S (1993) Zinc potentiates agonist-induced currents at certain splice variants of the NMDA receptor. Neuron 10:943-954.

Ishii T, Moriyoshi K, Sugihara H, Sakurada K, Kadotani H, Yokoi M, Akazawa C, Shigemoto R, Mizuno N, Masu M, Nakanishi S (1994) Molecular characterization of the family of the $N$-methyl-D-aspartate receptor subunits. J Biol Chem 269:2836-2843.

Kelso SR, Nelson TE, Leonard JP (1992) Protein kinase C-mediated enhancement of NMDA currents by metabotropic glutamate receptors in Xenopus oocytes. J Physiol (Lond) 449:705-718.

Kreig P, Melton DA (1984) Functional messenger RNAs are produced by SP6 in vitro transcription of cloned cDNAs. Nucleic Acids Res 12:7057-7070.

Krupp JJ, Vissel B, Heinemann SF, Westbrook GL (1996) Calciumdependent inactivation of recombinant $N$-methyl-D-aspartate receptors is NR2 subunit specific. Mol Pharmacol 50:1680-1688.

Kutsuwada T, Kashiwabuchi N, Mori H, Sakimura K, Kushiya E, Araki K, Meguro H, Masaki H, Kumanishi T, Arakawa M, Mishina M (1992) Molecular diversity of the NMDA receptor channel. Nature 358:36-41.

Laurie DJ, Putzke J, Zieglgänsberger W, Seeburg PH, Tölle TR (1995) The distribution of splice variants of the NMDAR1 subunit mRNA in adult rat brain. Mol Brain Res 32:94-108.

Leonard JP, Kelso SR (1990) Apparent desensitization of NMDA responses in Xenopus oocytes involves calcium-dependent chloride current. Neuron 4:53-60.

Lin JW, Wyszynski M, Madhavan R, Sealock R, Kim JU, Sheng M (1998) Yotiao, a novel protein of neuromuscular junction and brain that interacts with specific splice variants of NMDA receptor subunit NR1. J Neurosci 18:2017-2027.

Lozovaya N, Klee M (1995) Phorbol diacetate differentially regulates the $N$-methyl-D-aspartate (NMDA) and non-NMDA receptormediated components of the rat hippocampal excitatory postsynaptic currents. Neurosci Lett 189:101-104.

Maniatis T, Fritsch EF, Sambrook J (1982) Molecular cloning. Cold Spring Harbor, NY: Cold Spring Harbor Laboratory.

Miledi R, Parker I (1984) Chloride current induced by injection of calcium into Xenopus oocytes. J Physiol (Lond) 357:173-183.

Monyer H, Sprengel R, Schoepfer R, Herb A, Higuchi M, Lomeli H, Burnashev N, Sakmann B, Seeburg PH (1992) Heteromeric NMDA 
receptors: molecular and functional distinction of subtypes. Science 256:1217-1221.

Monyer H, Burnashev N, Laurie DJ, Sakmann B, Seeburg PH (1994) Developmental and regional expression in the rat brain and functional properties of four NMDA receptors. Neuron 12:529-540.

Mori H, Yamakura T, Masaki H, Mishina M (1993) Involvement of the carboxyl-terminal region in modulation by TPA of the NMDA receptor channel. NeuroReport 4:519-522.

Nicholl RA, Malenka RC (1995) Contrasting properties of two forms of long-term potentiation in the hippocampus. Nature 377:115-118.

Obokata K, Kamiya H, Ozawa S (1997) Differential effects of phorbol ester on AMPA and NMDA components of excitatory postsynaptic currents in dentate neurons of rat hippocampal slices. Neurosci Res 29:171-179.

Paoletti P, Ascher P (1994) Mechanosensitivity of NMDA receptors in cultured mouse central neurons. Neuron 13:645-655.

Portera-Cailliau C, Price DL, Martin LJ (1996) N-methyl-D-aspartate receptor proteins NR2A and NR2B are differentially distributed in the developing rat central nervous system as revealed by subunit-specific antibodies. J Neurochem 66:692-700.

Richardt G, Federolf G, Habermann E (1986) Affinity of heavy metal ions to intracellular $\mathrm{Ca}^{2+}$-binding proteins. Biochem Pharmacol 35:1331-1335.

Saybasili H (1998) The protective role of mild acidic $\mathrm{pH}$ shifts on synaptic NMDA current in hippocampal slices. Brain Res 786:128-132.

Sheng M, Cummings J, Roldan LA, Jan YN, Jan LY (1994) Changing subunit composition of heteromeric NMDA receptors during development of rat cortex. Nature 368:144-147.

Sigel E, Baur R, Malherbe P (1994) Protein kinase C transiently activates heteromeric $N$-methyl-D-aspartate receptor channels independent of the phosphorylatable C-terminal splice domain and of consensus phosphorylation sites. J Biol Chem 269:8204-8208.

Sihra TS, Piomelli D, Nichols RA (1993) Barium evokes glutamate release from rat brain synaptosomes by membrane depolarization: involvement of $\mathrm{K}^{+}, \mathrm{Na}^{+}$and $\mathrm{Ca}^{2+}$ channels. $\mathrm{J}$ Neurochem 61:1220-1230.

Sircar R, Follesa P, Ticku MK (1998) Postnatal phencyclidine treatment differentially regulates $N$-methyl-D-aspartate receptor subunit mRNA expression in developing rat cerebral cortex. Mol Brain Res 40:214-220.

Sugihara H, Moriyoshi K, Ishii T, Masu M, Nakanishi S (1992) Structures and properties of seven isoforms of the NMDA receptor generated by alternative splicing. Biochem Biophys Res Commun 185:826-832.

Tang C-M, Dichter M, Morad M (1990) Modulation of the N-methyl-Daspartate channel by extracellular $\mathrm{H}^{+}$. Proc Natl Acad Sci USA 87:6445-6449.

Tingley WG, Roche KW, Thompson AK, Huganir RL (1993) Regulation of NMDA receptor phosphorylation by alternative splicing of the C-terminal domain. Nature 364:70-73.

Tingley WG, Ehlers MD, Kameyama K, Doherty C, Ptak JB, Riley CT, Huganir RL (1997) Characterization of protein kinase A and protein kinase C phosphorylation of the $N$-methyl-D-aspartate receptor NR1 subunit using phosphorylation site-specific antibodies. J Biol Chem 272:5157-5166.

Traynelis SF, Cull-Candy SG (1991) Pharmacological properties and $\mathrm{H}+$ sensitivity of excitatory amino acid receptor channels in rat cerebellar granule neurones. J Physiol (Lond) 433:727-763.

Traynelis SF, Hartley M, Heinemann SF (1995) Control of proton sensitivity of the NMDA receptor by RNA splicing and polyamines. Science 268:873-876.

Tsien JZ, Huerta PT, Tonegawa S (1996) The essential role of hippocampal CA1 NMDA receptor-dependent synaptic plasticity in spatial memory. Cell 87:1327-1338.

Urushihara H, Tohda M, Nomura Y (1992) Selective potentiation of $N$-methyl-D-aspartate-induced current by protein kinase C in Xenopus oocytes injected with rat brain RNA. J Biol Chem 267:11697-11700.

Wagner DA, Leonard JP (1996) Effect of protein kinase-C activation on the $\mathrm{Mg}^{2+}$-sensitivity of cloned NMDA receptors. Neuropharmacology 35:29-36.

Watanabe M, Inoue Y, Sakimura K, Mishina M (1993) Distinct distributions of five $N$-methyl-D-aspartate receptor channel subunit mRNAs in the forebrain. J Comp Neurol 338:377-390.

White M, Aylwin M (1990) Niflumic and flufenamic acids are potent reversible blockers of $\mathrm{Ca}^{2+}$-activated $\mathrm{Cl}^{-}$channels in Xenopus oocytes. Mol Pharmacol 37:720-724.

Williams K, Russell SL, Shen YM, Molinoff PB (1993) Developmental switch in the expression of NMDA receptors occurs in vivo and in vitro. Neuron 10:267-278.

Wyszynski M, Lin J, Rao A, Nigh E, Beggs AH, Craig AM, Sheng M (1997) Competitive binding of $\alpha$-actinin and calmodulin to the NMDA receptor. Nature 385:439-442.

Wyszynski M, Kharazia VN, Shanghvi R, Rao A, Beggs AH, Craig AM, Weinberg RJ, Sheng M (1998) Differential regional expression and ultrastructural localization of $\alpha$-actinin-2, a putative NMDA receptoranchoring protein, in rat brain. J Neurosci 18:1383-1392.

Yamakura T, Mori H, Shimoji K, Mishina M (1993) Phosphorylation of the carboxyl-terminal domain of the zeta1 subunit is not responsible for potentiation by TPA of the NMDA receptor channel. Biochem Biophys Res Commun 196:1537-1544.

Yamazaki M, Mori H, Araki K, Mori KJ, Mishina M (1992) Cloning, expression and modulation of a mouse NMDA receptor subunit. FEBS Lett 300:39-45.

Zheng X, Zhang L, Durand GM, Bennett MVL, Zukin RS (1994) Mutagenesis rescues spermine and $\mathrm{Zn}^{2+}$ potentiation of recombinant NMDA receptors. Neuron 12:811-818.

Zheng X, Zhang L, Wang AP, Bennett MVL, Zukin RS (1997) Ca ${ }^{2+}$ influx amplifies protein kinase $C$ potentiation of recombinant NMDA receptors. J Neurosci 17:8676-8686.

Zhong J, Carrozza DP, Williams K, Pritchett DB, Molinoff PB (1995) Expression of mRNAs encoding subunits of the NMDA receptor in developing rat brain. J Neurochem 64:531-539.

Zukin RS, Bennett MVL (1995) Alternatively spliced isoforms of the NMDARI receptor subunit. Trends Neurosci 18:306-313. 